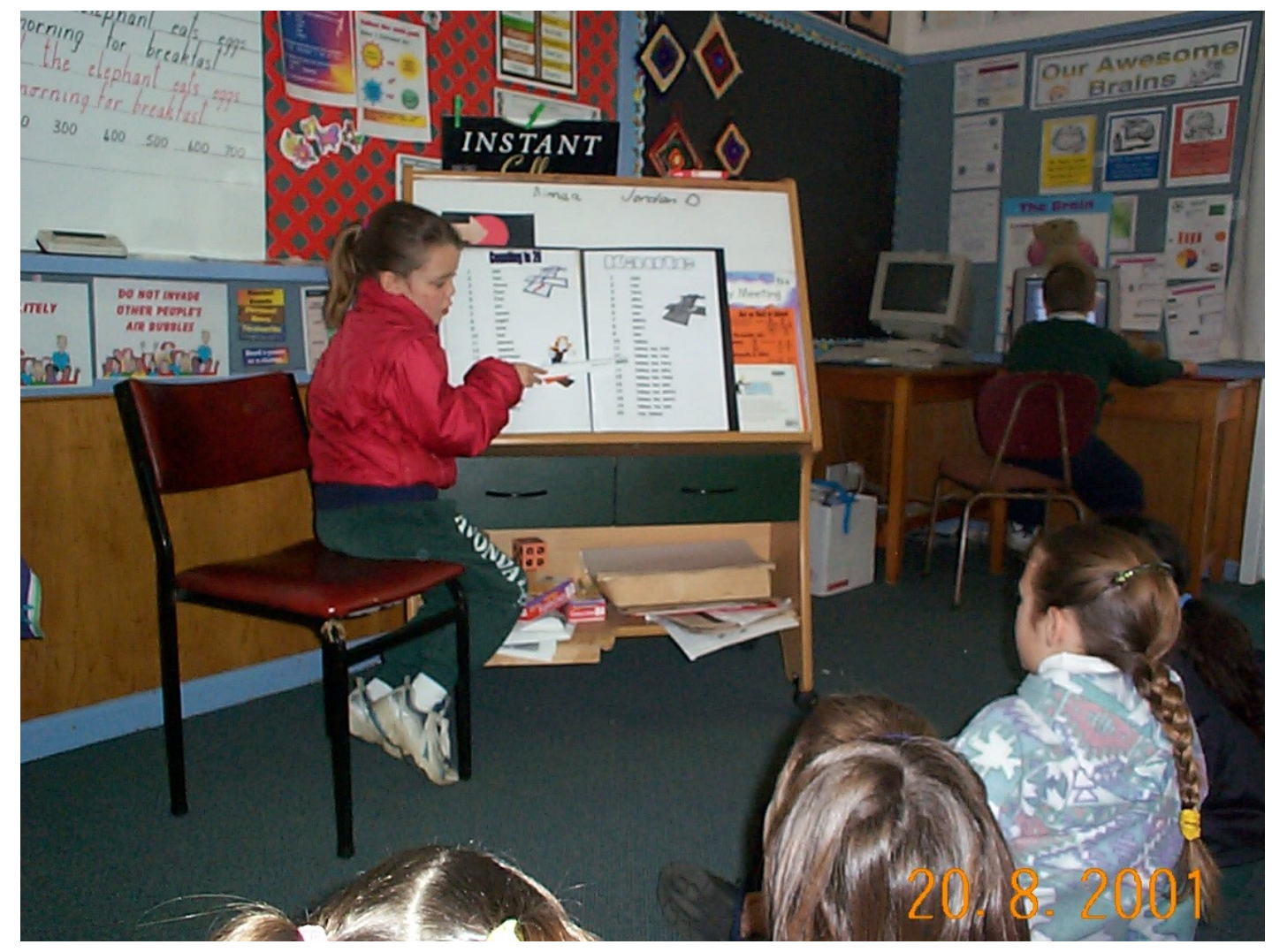

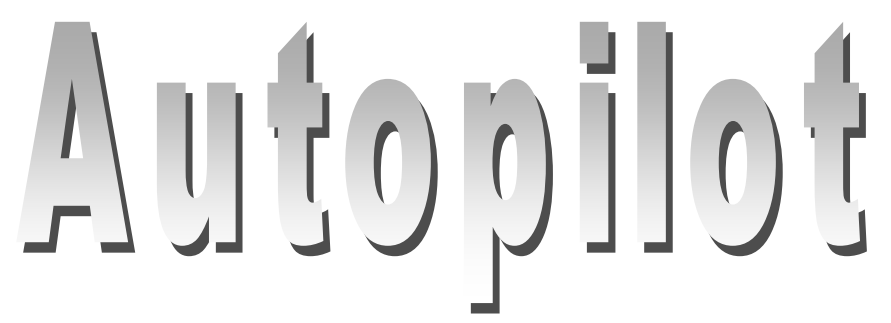


Approved by

Chairperson of Supervisory Committee

Programme Authorized to Offer Degree

Date 


\title{
AN EVALUATION OF THE EFFECTIVENESS OF THE VERBAL CHAINING ELEMENTS OF "AUTOPILOT", A ROTE LEARNING PROGRAMME USED BY TEACHERS OF YR. 1-3 STUDENTS.
}

\author{
Kevin White \\ A thesis submitted in partial fulfilment of the requirements \\ for the degree of Master of Arts (in education)
}

Victoria University of Wellington

2004 


\section{Acknowledgements}

My special thanks is extended to the teachers and pupils who so willingly agreed to take part in the research and who responded so positively to the introduction of the programme in their classrooms.

I wish to thank Sue Garden - Bachop for allowing her original "Autopilot" concept to be used and developed into its present format. Her good wishes and support are very much appreciated. 


\begin{abstract}
A rote-learning programme, “Autopilot”, was used for a five-week period with two classes of Year 2 students, to teach the verbal chains: days of the week, months of the year, the alphabet, counting in ones, twos, fives and tens. A quasi-experimental multiple baseline was used with the two classes. After five weeks of instruction all seven chains were reassessed and the percentage of positive changes were compared. The class receiving Autopilot made an average positive change increase of 80 . 05\%. The class receiving a regular class programme over the same five-week period, made a positive change increase of $39.5 \%$. When the treatment was switched, the class who had received Autopilot continued to maintain or increase the length of the chain. This research shows that the use of a rote learning programme, such as Autopilot, is an appropriate tool for the teaching of verbal chains in junior school classes.
\end{abstract}


Acknowledgements

Page

Abstract

i

Contents

ii

List of Tables

iii

List of Tables

$i v-v$

List of Figures

Introduction

Chapter 1

The key theories underpinning Autopilot

Chapter 2

The specifics of Autopilot

17

Chapter 3

Methodology

31

Research Design

Setting

Participants

Procedures

Instruments

Data Collection

Data Analysis

Chapter 4

Research Findings

41

Chapter 5

Conclusions, Discussion, Limitations and

Suggestions for Future Research

References

Permission for the use of Autopilot programmes

Appendix A

Appendix B

Appendix C

Appendix D

Appendix E

Appendix F

Appendix G

Appendix $\mathrm{H}$
“The Days of the Week,” a typical Autopilot page.

List of concepts from the Autopilot guidelines.

Consent form for the Board of Trustees.

Consent form for teachers (reduced format).

Consent form for parents and students (reduced format).

Assessment record sheet.

Student questionnaire and record sheet (reduced format).

Teacher questionnaire and record sheet (reduced format). 


\section{List of Tables}

$\underline{\text { Table } 1}$

Number of correct responses of students in Class 1 and the direction of the change for the three assessments of the alphabet chain.

Table 2

Number of correct responses of students in Class 2 and the direction of the change for the three assessments of the alphabet verbal chain.

$\underline{\text { Table } 3}$

Number of correct responses of students in Class 1 and the direction of the change for the three assessments of the months of the year verbal chain.

\section{Table 4}

Number of correct responses of students in Class 2 and the direction of the change for the three assessments of the months of the year verbal chain.

$\underline{\text { Table } 5}$

Number of correct responses of students in Class 1 and the direction of the change for the three assessments of the counting in 1s verbal chain.

$\underline{\text { Table } 6}$

Number of correct responses of students in Class 2 and the direction of the change for the three assessments of the counting in 1s verbal chain.

Table 7

Number of correct responses of students in Class 1 and the direction of the change for the three assessments of the counting in $2 \mathrm{~s}$ verbal chain.

$\underline{\text { Table } 8}$

Number of correct responses of students in Class 2 and the direction of the change for the three assessments of the counting in 2s verbal chain.

\section{$\underline{\text { Table } 9}$}

Number of correct responses of students in Class 1 and the direction of the change for the three assessments of the counting in 5 s verbal chain.

$\underline{\text { Table } 10}$

Number of correct responses of students in Class 2 and the direction of the change for the three assessments of the counting in $5 \mathrm{~s}$ verbal chain.

\section{$\underline{\text { Table } 11}$}

Number of correct responses of students in Class 1 and the direction of the change for the three assessments of the counting in 10s verbal chain. 
Number of correct responses of students in Class 2 and the direction of the change for the three assessments of the counting in 10s verbal chain.

$\underline{\text { Table } 13}$

Number of correct responses of students in Class 1 and the direction of the change for the three assessments of the twenty selected letter names.

Table 14

Number of correct responses of students in Class 2 and the direction of the change for the three assessments of the twenty selected letter names.

$\underline{\text { Table } 15}$

Number of correct responses of students in Class 1 and the direction of the change for the three assessments of twenty letter sounds.

$\underline{\text { Table } 16}$

Number of correct responses of students in Class 2 and the direction of the change for the three assessments of twenty letter sounds.

$\underline{\text { Table } 17}$

Percentage comparison of correct responses for the four most difficult letter sounds Ee Uu Xx Qq for Class 1 taken over three assessments.

$\underline{\text { Table } 18}$

Percentage comparison of correct responses for the four most difficult letter sounds Ee Uu Xx Qq for Class 2 taken over three assessments.

Table 19

Percentage comparison for all verbal chains for Class 1 with the intervention and Class 2 without the intervention. 


\section{List of Figures}

Figure 1 Phases of the research

Figure 2

A percentage comparison for Class 1 of letter sounds E U X \& Q for the three assessments.

Figure 3

A percentage comparison for Class 2 of letter sounds E U X \& Q for three assessments.

Figure 4

59

A comparison of the two classes for all the Autopilot elements, showing the percentage of students who made positive changes with the Autopilot programme (Class 1) and with the regular programme (Class 2) during a the first assessment.

(After five weeks of instruction).

Figure 5

The percentage of students from Class 1 who were able to maintain of increase the length of the verbal chain after ten-weeks.

(Five weeks of intervention and five weeks of maintenance). 


\section{Introduction}

This research is an investigation into a teaching tool, Autopilot used by teachers of junior school classes.

\section{Aim of the Research:}

This research study investigates the question:

Does a five week, 15 minutes per day whole class Autopilot programme, increase the Yr. 2 students' understanding and knowledge of the alphabet, days of the week, months of the year and rote counting, for students who have not reached proficiency and maintain the levels for those students who have reached proficiency?

\section{Description of Autopilot and its Contents}

The Autopilot book is a large A3 clear file shared book. Each page of the clear-file contains a key idea or concept, for example Days of the Week. The concepts that are included in Autopilot vary from class teacher to class teacher, but are usually numeracy or literacy based. Pages include: counting (in 1s, 2s, 5 s and 10s), days of the week, months of the year, shapes, transportation names, mihi, poems, vegetable and fruit names, lists of class names, times tables and punctuation names. A typical page in all Autopilots is "The Days of the Week" page. (See Appendix A). This page has the days listed, with a graphical representation (a calendar) to focus the reader. The class as a whole recites the page, often in the form of a chant, with the guidance and prompting of a student (tutor) selected and trained by the teacher.

\section{A Brief History of Autopilot}

The researcher developed the programme from a concept originating with Sue Garden - Bachop (nee Garden). The original programme was used in the early 90s with children in a hanau class of a decile 1 primary school class of Yr. 1-3s. This original programme consisted of a series of cardboard sheets containing concepts ranging from counting to recognition of colours, shapes, basic words and verbal 
chains (alphabet - counting in 5s). The teacher used the direct instruction model with the hanau. Sue Garden - Bachop has given the researcher the right to use the name and to develop the programme into its present format.

\section{Current Use in Schools}

The programme has evolved over the years into its present format. Autopilot is used in more than twenty schools. Teachers use it as a preparatory tool for the literacy and mathematical development of year one to three students. They regard the programme as a rote learning programme and consider that it is consistent with the National Curriculum, particularly the Mathematics and English curricula, that state that students need to recite rote number sequences (verbal chains) and the alphabet. It is regarded by these teachers as a way of increasing conceptual understanding in basic literacy and numeracy knowledge.

As the book is in a clear file format, teachers are free to add pages on any concept they wish, but most use reproductions of the pages presented on the Autopilot CD produced by the Aranui resource teachers of learning and behaviour service (Aranui RTLB). This CD lists a large variety of concepts (Appendix B) including verbal chains, facts, tables and charts of relevant programmes used in junior classes.

\section{How the Programme is used}

Before the day begins, the teacher has prepared and marked which pages the class need to recite; some days they recite the whole book. The book is used daily with the whole class reciting together. The students recite each page of the Autopilot book, following the lead of a class member who is a trained tutor. The trained tutor recites and encourages the rest of the class to respond. The trained tutor uses a pointer (usually a magic wand) that focuses the learner (tutee) to the print and ensures that the rhythm of the language is emphasised. The teacher uses a "Model, Lead, Test" routine and scaffolded procedures to train the tutors. The teacher has previously modelled how Autopilot is to be presented to the class, until sufficient students have been trained to take over as tutors. The scaffolding procedure relies on the teacher to begin the programme by sharing, encouraging and modelling the process. The teacher then gradually allows students to take greater control of the process, through 
modelling and rehearsing the correct process, until the student is able to run the programme with a minimum of teacher input.

\section{Reasons for the Research}

There has been no systematic evaluation of the Autopilot programme, although it is widely used throughout Canterbury schools. Throughout its use over the last 20 years, teachers have reported positively on its effectiveness and students have participated in the programme with enthusiasm. Anecdotal evidence suggests there are a number of factors that attract the students to the task.

1. The pointer focuses the learner to the print.

2. The rhythm of the language is emphasised. It is repetitive and "chant-like" in its presentation.

3. The book is used every day and is a familiar part of the programme.

4. It is non-threatening. Students can either join in and chant known pages, attempt just some of the familiar passages or just observe. There is no compulsion to verbalise.

Experience suggests that teachers who use the programme consider the book to be an inclusive practice, as all students, regardless of ability participate at the same time. The programme is a peer mediated instruction programme, as it is directed and led by students for students. Teachers regard the programme as a teaching tool, as it covers many of the prescribed curriculum concepts of literacy and numeracy. When not in direct use by the whole class, it is used as a resource tool for students to refer to when they need; a familiar shared book to read, a source of spelling words, key concepts of maths (shapes - counting sequences and so forth) or a poetry book.

The researcher has a personal interest in the programme. He was a teacher at Aranui Primary with Sue Garden-Bachop and developed her initial programme, from its cardboard page concept to the present A3 clear file format. The researcher also works for the Aranui RTLB service, which has a vested interest in the research, as this service makes the CDs available to schools throughout Canterbury. The RTLB service is very aware that the programme is widely used and wishes to ensure that the resource has been evaluated for its effectiveness. 
This research has been designed to provide an evaluation into the effectiveness of only some elements of the programme, the verbal chains. These verbal chains are:

The alphabet,

Counting in $1 \mathrm{~s}, 2 \mathrm{~s}, 5 \mathrm{~s}$ and $10 \mathrm{~s}$,

The days of the week,

The months of the year.

The RTLB service is a promoter of inclusive practice. One of the aims in RTLB Guidelines (Ministry of Education, 2001) states that the role of the RTLB is to upskill classroom teachers to be more inclusive. Section 2.1 of the guidelines (Ministry of Education, 2001) state that RTLB "should become skilled in the principles and practices of adapting the curriculum in a way that is inclusive and least intrusive as possible” (Section 2.1, no page number). This section 2.1 also states that RTLB should be "skilled in teaching methodologies known to be helpful for less successful learners and diverse groups of students.” The Aranui RTLB service and the schools they serve, consider Autopilot to be a successful programme and an inclusive practice and actively promote its use throughout their schools. This research will examine whether the use of Autopilot as an inclusive practice is justified and whether its use actively increases students' knowledge and maintenance of verbal chains.

The New Zealand Curriculum Framework (NZCF) (Ministry of Education, 1993) is the official policy for teaching, learning and assessment in New Zealand schools. There are clear indications within the NZCF, that there is an expectation that teachers will use cooperative and inclusive strategies. There are eight groupings of essential skills that must be taught. One of these, social and cooperative skills, states that students should develop good relationships with others and work in co-operative ways to achieve common goals. Both the English in the New Zealand Curriculum (Ministry of Education, 1994) and the Mathematics in New Zealand Curriculum (Ministry of Education, 1992) support the notion of cooperative and inclusive teaching practices with suggestions for teachers of effective teaching practice using cooperative and inclusive strategies. These individual curricula also remind teachers of their commitment to the teaching of the essential skills, which include cooperative and inclusive practices. 
Special Education 2000 states as one of its aims, that New Zealand will have a world-class inclusive educational system (Ministry of Education, 1996). One of the initiatives towards meeting this aim was the creation of the Resource Teacher of Learning and Behaviour (RTLB) service. The RTLB service is bound by a code of professional standards and work within a set of guidelines (Ministry of Education, 2001). The code of professional standards, lists eight vital components. Two of the most important standards are professional knowledge and teaching techniques.

\section{a) Professional knowledge - Professional standards.}

Demonstrates a significant depth of knowledge in the theory and practical application of:

- a range of inclusive strategies based on effective practice

- learning and assessment theory

- the current issues and initiatives in education, including Maori education

\section{b) Teaching techniques - Professional standards.}

Demonstrates expertise and refined strategies in supporting staff in the development and practise of:

- inclusive teaching programmes

- effective programme implementation

- assessment of learning and behaviour

- $\quad$ staff support and advice

Cooperative learning and peer mediated instruction have become recognisable methods of increasing inclusive practices in classrooms (Brown \& Thomson, 2000). Teachers who use Autopilot consider that it is an inclusive practice.

The government in its Report on the Literacy Taskforce (Ministry of Education, 1999) set an objective, that by the year 2005 every student turning nine will be able to read. The report then states that one of the measures of success is that a nine year old who is reading for success will have the skills to decode and be able to use phonics (letter-sound) combinations. For this objective to be achieved by the year 2005, these nine-year-old students are currently in Yr 3 classes. If teachers of Yr 2 3 students are to meet this objective, then they need to have in place appropriate strategies to teach phonics / letter sound combinations. 


\section{Chapter 1}

\section{The key theories underpinning Autopilot}

This chapter will examine the key educational theories that underpin the Autopilot programme. The chapter will also examine how these theories are often linked and how aspects of each theory work together to explain how learning might occur using the programme.

The key educational theories are: 1) the information processing model of whom (Gagné, 1985) is one of the key proponents, 2) behaviourism, in particularly; operant conditioning, schedules of reinforcement (Skinner, 1938) and their relationship with direct instruction practices (Carnine, Silbert \& Kameenui, 1997) and 3) the social constructivist model (Vygotsky, 1978) and social learning theory (Bandura, 1977).

The examination of the information-processing model (Gagné, 1985) will explain how, through the use of rote learning practice, concepts or information presented in Autopilot may move from short term memory to long term memory. Gagné developed eight conditions of learning and five major categories of human capabilities or levels of learning. Gagné's conditions of learning were extended in 1992 to include nine instructional events and the corresponding cognitive processes. This section will also examine rote learning, its various related names and the implications behind rote learning practice.

The examination of behaviourism will focus primarily on operant conditioning, operant behaviour and schedules of reinforcement. It will also examine its relationship to direct instructional teaching.

The two theories, information processing model and operant conditioning, can be combined to develop a direct instruction model in a group instruction situation. This appears to be preferred by teachers, as the learning occurs in a social setting. The social constructivist model is examined, particularly the zone of proximal (ZPD), scaffolding, peer mediated instruction and modelling and their interrelationship in a group setting. 


\section{The Information Processing Model}

There are many theoretical models for the process of how short term memory becomes long-term memory. One of the key proponents and theorists was Gagné, who contributed to the information-processing model of learning (Gagné, 1985). This model states that there is a series of stages through which information is processed. At the first stage, the sensory receptor stage, information is received by receptors, for example eyes / ears and is held for a few hundredths of a second. At this stage, selective perception acts as a filter, which causes some aspects of the information to be ignored and others to be attended to. The information that is attended to is then passed on to the second stage, short-term memory. At this stage, storage is short and limited and is often lost unless it is rehearsed.

If the information is linked with prior knowledge, then the information is passed on to long-term memory. This linking or encoding process is sometimes called learning. Information that is not passed on to long-term memory is lost. Gagné recognised that for encoding to take place, there needs to be the regular rehearsal of information. Rote learning procedures can be used as a process for the acquisition of long-term memory.

Gagné (1985) identified eight conditions of learning. Of these conditions, Gagné's third and fourth conditions, verbal chaining and verbal associations, have direct implications for moving information from short to long term memory.

Gagné (1985) defines verbal chaining as "the connection of a set of individual Ss -$>$ Rs in a sequence” (p. 68). Verbal chaining allows the students to successfully “chunk” groups of information into conceptual or categorized groups (Nolan, 1973). Verbal association is "making associations from the verbal connections" (p. 69) (Gagné, 1985).

Rote learning relies heavily on both verbal chaining and verbal association through students reciting over and over, a sequence of related signals, for example the alphabet sequence ABC. Verbal chaining relies on the sequencing of associated elements (Kameenui \& Simmons, 1990). 
Gagné (1985) also identified five major categories of human capabilities or levels of learning. These were verbal information, intellectual skills, cognitive strategies, motor skills and attitudes.

Verbal information is the first or initial level of learning, for example learning the alphabet. For successful verbal information to occur, there needs to be regular practise of verbal chains or associations. In order to retain information, Gagné proposed that teachers ensure that students learn lower-order skills first and build on them. In this way schema are formed.

In 1992 Gagné, Briggs and Wager extended the conditions of learning theory to integrate nine instructional events and their corresponding cognitive processes. These are:

1. gaining attention (reception)

2. informing learners of the objectives (expectancy)

3. stimulating recall of prior learning (retrieval)

4. presenting the stimulus (selective perception)

5. providing learning guidance (semantic encoding)

6. eliciting performance (responding)

7. providing feedback (reinforcement)

8. assessing performance (retrieval)

9. enhancing retention and transfer (generalisation)

Of these processes, reception, expectancy and retrieval relate to rote learning theory.

Rote learning is described in a variety of ways. Some of rote learning's related names are: memorisation (Smilkstein, 1993), learning by heart (Cook, 1994; Gill, 1983), memorability (Gill, 1983), drill (Severson, undated), reciting (Baines \& Stanley, 2000; Smilkstein, 1993; Topliss, 1989), rehearsal (Gagné, 1985) and chunking (Nolan, 1973). All have the same process, repeated chanting of sequences until the recipient can retrieve and verbalise back verbatim.

Smilkstein (1993) defined rote learning as “memorisation,”

It is a process by which students are able to recite back, but may not be able to necessarily understand what it means and typically can't use it in any 
thoughtful or creative way ... however some rote knowledge might be useful, as when students memorize the multiplication tables. (p. 16).

Severson, (undated) calls rote learning drill, a rapid and intensive rote trial. Drill has repeated associations of a serial nature. Others call rote learning learning by heart (Cook, 1994; Gill, 1983) or repetitive learning.

Nolan (1973) defines rote learning as a "chunking process” in contrast to concept learning, which is “categorizing." This technique of chunking, or learning 'chunks' of information, by regular repetition (Mitchell \& Martin, 1997; Nolan 1973) is regarded as a useful technique for memorisation

Rote learning, as an educational tool, has a chequered history. Educators, depending on the outcomes, can view rote learning either positively or negatively. If students are seen to be progressing, learning, then rote learning is viewed as a positive strategy. If the intention is for the students to memorize and understand, then it is also viewed positively (Smilkstein, 1993). Kember (1996) undertook a variety of trials on rote learning practice and found that the most effective rote learning was when trials were seen to be both useful for memorization and understanding.

Rote learning also has a long history of whole class involvement. Reciting the times tables is a universal whole class practice and has recently been positively assessed as a whole class practice (Baines \& Stanley, 2000; Smilkstein, 1993; Topliss, 1989). These authors all advocate that reciting and repetition builds a database from which more constructivist strategies can build. Baines and Stanley (2000) write, "the worst insult that can be leveled at a teacher is that a lesson involves rote learning, however, there is a place for deliberate, specialized ordeal of building expertise" (p. 2).

Rote learning can be regarded as active learning and confirms the view (Katz, 1986) that young students learn most efficiently when they are engaged in interaction, rather than merely receptive or passive participants. Stevens and Rosenshine (1981) examined effective teaching practice and identified that effective teachers use four key strategies: group instruction, teacher directed instruction, academic focus and encouragement of individualism. They note that demonstration - prompt - practice is a very effective teaching strategy. 
The most effective process for teaching a clearly defined skill involves three steps. The first step is a demonstration of the skill or presentation of the rule or general principle. The second step is student practice of each of the component parts of the skill, with the teacher providing prompts and corrections. The third step is independent student practice (p. 3).

There is a distinctive difference between rote learning and serial learning. Rote learning is a process of building and developing a base of knowledge by repeating a process until it is embedded in long-term memory. Serial learning although a rote process has chains of related or associated elements that form a natural progression. Examples of these are, phone numbers, letters in a name, elements in a valency table and the months of the year sequence. Severson defined serial learning, (undated) as an ability to repeat a chain of associations, where the first leads to the second, the second to the third and so on in a single correct order.

Rote learning should not be merely a repetitive practice for memorisation, but there is an intention that the students gain understanding as well (Kember, 1996). Repetition provides a method of anchoring language understanding on the concepts. Through daily exposure to the necessary concepts students gain the understanding of the terminology (Gagné, 1985).

In 1970, Junge undertook a major English as a second language study, to find the most effective method of learning unfamiliar words. Her finding showed that rote learning, undertaken as serial learning, was the most effective method of learning these selections.

Any rote learning activity needs some method of ensuring that students are focused on the task. The students also need to be reinforced, so that sequences move from short to long-term memory. Daily presentation of the material alone will not ensure that learning occurs, as the learner needs to be focused and committed to the task at hand. The behavioural approach relies on both a stimulus (the material being rote learned) and some reinforcement, particularly a reinforcement schedule for learning to occur. 


\section{Operant Conditioning}

This next section of the chapter looks at how the behavioural approach, particularly operant conditioning, schedules of reinforcement and direct instruction may support the information processing model to explain how rote learning occurs.

In 1938, B.F. Skinner defined operant conditioning thus: "If the occurrence of an operant is followed by presentation of a reinforcing stimulus the strength is increased” (p. 21). He said that the organism is free to respond at any time, and conditioning is measured by the rate of responding. There were some conditions. The subject had to be active and likely to be using consciously controlled behaviours.

There are four basic tenets of operant conditioning (Skinner, 1938). The first is that an operant is a response that has some effect on the world. The second states that a reinforcer increases the probability that the operant preceding it will occur again. The third states that positive reinforcers will strengthen a response if they are experienced after that response occurs. There are also negative reinforcers that strengthen a response if they are removed after it occurs - for example pain, or threats of punishment.

Operant behaviour is formed and strengthened by a number of factors (Skinner, 1938; Cooper, Heron \& Heward, 1987). The behaviour is usually shaped through reinforcement of successive approximations of the desired response. Primary reinforcers that are inherently rewarding and increase the desired affect, for example verbal praise or food. Sometimes it is easier for teachers to use secondary reinforcers. These are reinforcers that people learn to like because of their association with primary reinforcers (for example money - its reinforcing power lies in its association with the rewards it can bring, or smiles and encouragement). For reinforcement to be successful, there needs to be a hierarchy of reinforcement developed through a well constructed schedule of reinforcement that ensures that the speed, the regularity of the reinforcement and the size of the reinforcement have to be taken into account. If these all occur, then the behaviour may be effectively conditioned. The key to changing behaviour in the classroom is the correct allocation of a schedule of reinforcement. 
There are four basic schedules of reinforcement used (Ferster \& Skinner, 1957). All others are combinations or variations of these basic four:

Fixed Ratio (FR). This occurs when reinforcement is given after a fixed number of responses, for example FR-1 indicates one reinforcement for one response, FR-5, indicates one reinforcement for five responses.

Variable Ratio (VR). This occurs when reinforcement is given after a variable number of responses. VR-5 indicates one reinforcement for on average every five responses.

Fixed Interval (FI). This occurs when reinforcement occurs after a fixed time interval has passed. This is usually measured in seconds, so FI-10 would indicate reinforcement for each response after 10 seconds.

Variable Interval (VI). This occurs when reinforcement occurs after a variable time has passed. This is also measured in seconds, so VI-10 indicates reinforcement on average after 10 seconds has elapsed.

Teachers who are aware of the power in reinforcement use a variety of reinforcement schedules to encourage positive learning to occur. Teachers have indicated that during Autopilot sessions they actively encourage student participation by giving variable reinforcement. By successfully completing a rote learned sequence, students receive verbal praise from their teacher or tutor.

An operant must be defined in terms of its relationship to controlling variables (Skinner, 1938). Operant behavior is any behaviour whose probability of occurrence is determined by its history of consequences. In terms of operant conditioning (Skinner, 1938) students are more likely to respond positively if the event is followed by a favourable response. Using this definition, students are more likely to contribute if they are positively praised and / or enjoy participating. Operant conditioning (Cooper et al., 1987) occurs when the probability is determined by its history of consequences. Success breeds success.

The Direct Instruction approach (Carnine et al., 1997) provides an approach to operant conditioning that can be used in the classroom, either through individual 
conditioning or using a class conditioning approach. Direct instruction procedures use Skinner's operant conditioning processes as they rely heavily on schedules of reinforcement through a hierarchy including praise and rewards. Direct Instruction has been identified as a successful technique for skill acquisition. Direct Instruction relies on individual students being prompted in sequence learning. A class that recites the alphabet, is undertaking direct instruction, but in a class setting.

Teachers are aware that no matter what approach they use, it is impractical and impossible to overlook the impact that social interaction plays within the classroom. The classroom is a learning environment that is social in nature. The learning occurs in a social context. The remainder of this chapter considers the implications and impact that the social environment plays in learning and its relationship to the information-processing model, particularly the rote learning approach, operant conditioning and direct instruction.

\section{The Social Constructivist Model and Social Learning Theory}

There are two theories that explain how the classroom interactions can enhance learning. The first is an interactive social approach, the social constructivist model (Vygotsky, 1978) based on a premise that all knowledge is social in nature and that the learning occurs in a context of social interactions where knowledge is constructed rather than absorbed (Ausubel, 1968) and this leads to understanding. Learners take risks, accept challenges and, through the opportunities given, then reconstruct the information so that it makes sense to them. This theory is reliant on positive interactions with schedules of reinforcement. The second is a more passive observational approach, the social learning theory (Bandura, 1977). This theory states that learning can occur in the absence of direct reinforcement through observations of models through observing, reading or making observations of the world.

According to Vygotsky, all of these processes occur in a zone of proximal development. This zone is a learning zone. The zone is a measure of what a student already knows and what he has the ability to learn with the help of a more capable peer or tutor. It is the difference or distance between what the student's actual developmental level is and the potential development as determined through problem 
solving, with adult (teacher) guidance and with help of more capable peers (Wertsch, 1985). The guidance is usually referred to as scaffolding. For example, when reciting the alphabet, if there is a copy of the alphabet to view, then a model is available to scaffold new ideas.

Scaffolding was first described by Wood, Bruner and Ross (1976) as a metaphor, to characterize the type of help provided by an expert to a novice. It is essentially a method of the teacher controlling those elements of the task that are initially beyond the student's capability, thus permitting the student to concentrate upon and complete only those elements that are within the student's range of competence. Learners connect with previous known information, but gradually become independent as more and more is scaffolded by the teacher. By using scaffolded procedures "understanding can be extended far beyond that which they could reach alone" (Pollard, 1997, p. 125). Bliss and Askew (1996) support scaffolding particularly for junior school teachers working in the areas of science and maths.

Teachers are aware of the power of peer interactions. Often the classroom is structured so that the learning environment encourages and includes student / student learning approaches. These approaches may use the scaffolded system of an expert (in this case a student) providing help to a novice (another student). Peer mediated instruction may include a variety of approaches including peer tutoring, cooperative learning approaches and modelling.

Peer mediated instruction is a widely researched educational intervention, defined as "instruction and intervention in an alternative classroom arrangement in which students take an instructional role with classmates or other students” (Hall \& Stegila, 2001). The concept of peer-mediated instruction grew from Rosenbaum's early research on applying techniques of drill and practice of computer-assisted instruction to language skills learning (Rosenbaum, 1973). This instruction directed students to work in pairs, interacting with one another according to structured pattern of dialogue. There is an extensive research literature in the areas of peer mediation and tutoring. In a meta-analysis on peer-mediated instruction, Johnson, Johnson and Stanne (2000) report : 
There are over 900 research studies validating the effectiveness of cooperative over competitive and individualistic efforts. This body of research has considerable generalizability since the research has been conducted by many different researchers with markedly different orientations working in different settings and countries and in eleven different decades, since research participants have varied widely as to cultural background, economic class, age, and gender, and since a wide variety of research tasks and measures of the dependent variables have been used (no page numbers).

Most of these studies were conducted since 1970. Of those, 164 studies positively evaluated the impact of a peer mediated instructional procedure on student achievement. In addition, Johnson, Johnson and Stanne (2000) report that “ All eight cooperative learning methods had a significant positive impact on student achievement” (no page numbers).

Many approaches have been developed in which students work in either pairs, dyads or small cooperative learning groups. They are most effective when students have been taught roles in the instructional process. They should be taught to be systematic, elicit responses and provide feedback. There are four characteristics for success common across all forms of peer-mediated instruction (Hall \& Stegila, 2001). The first is that for a programme to be successful there needs to be an assignment and training of students to the roles that they undertake. The second pointer to success is that the students instruct one another, one student acts as the tutor, the other as the tutee. However, the interaction and success is not only one-way. The most successful tutee peer programmes ensure that the tutee gives positive feedback on the success of the tutoring. Teachers cannot abrogate their responsibility for the learning to the students. Research shows that success occurs only when teachers monitor and facilitate programmes. The last characteristic is that the structures are designed to increase academic as well as social goals for all students.

Social learning theory takes a different approach. This theory (Bandura, 1977) emphasises the social origins of behaviour, in addition to the cognitive processes that influence human behaviour and functioning. Bandura (1977) explores the idea that learning can occur in the absence of direct reinforcement and that people can learn simply through observations of models, reading about what people do or by making general observations of the world around them. Modelling is a powerful learning tool 
regardless of whether the modelling is undertaken by a teacher or a peer (Bandura, 1977). Bandura proposed a four-stage scheme for the process involved in modelling (observational learning). The first stage involves incorporating the attentional process involved in modelling, the second refers to the retention or encoding of what has been observed, the third refers to the motor reproduction capacities and capabilities of the observer and the fourth stage is the imitation, the observer must be motivated to perform the behaviour.

Many researchers have supported modelling as a powerful learning tool. Anderson, Evertson and Brophy (1979) included modelling amongst their list of twenty-two principles for effective teaching practices amongst grade one classes. Effective teaching practice encompasses many educational theories, approaches and practices. These include; direct instruction, including Model-Lead-Test (Kameenui \& Simmons, 1990), modelling, peer mediated instruction and cooperative teaching.

Research on effective instruction emphasizes that effective teachers use students who have mastered an objective as tutors or models for other class members (Anderson, Evertson \& Brophy, 1979; Stevens \& Rosenshine, 1981; Gautrey, 1991). Effective instruction is also characterised by considerable teacher-led instruction, directed at either the whole class or a small group of students (Stevens \& Rosenshine, 1981). 


\section{Chapter 2}

\section{The specifics of Autopilot}

This chapter looks at two aspects of Autopilot by examining the content of the programme and the process through which learning may occur. This chapter aims to link the theories of: the information processing model, operant conditioning, schedules of reinforcement, direct instruction practices, the social constructivist model, scaffolded instruction and social learning theory, to the use of Autopilot in classrooms.

\section{Rote Learning within the NZCF}

Recent research on rote learning favours the author's stance that rote learning has a place in modern educational practice, if the skills that the students are acquiring (for example times tables, reciting of the alphabet) are educationally valid or are a stepping-stone to other skills.

The NZCF indicates that there is an expectation on teachers to use rote learning / rote teaching strategies. Rote learning is specifically mentioned as a strategy in the Mathematics in New Zealand Curriculum (Ministry of Education, 1992, p. 33). Students should be:

- Rote counting to 50 and counting forwards and backwards to and from 99 in 1s, 2s, 5s and 10s (both orally and using a calculator)

Mathematics in New Zealand Curriculum (Ministry of Education, 1992) states that students should be able to:

- Read aspects of time, including days of the week (p. 58), read time and know units of time - minute, hour, day, week, month and year (p. $62)$.

Within the English curriculum students must have an understanding of graphophonic cues, specifically letter names and sounds. The English in the New Zealand Curriculum (Ministry of Education, 1994) states the students should: 
- Select and read for enjoyment and information a range of written texts, beginning to use semantic, syntactic, visual and grapho-phonic cues to gain meaning. (p. 34)

Grapho-phonic cues are described as "the letters and patterns of letters, separately or in clusters, which enable readers to identify sounds" (p. 140). Teachers should ensure that students have a grasp of grapho-phonic cues and visual patterns "clusters of words / syllables / blends /letters - depending on how one wants to break the patterns up” (Clay, 1979, p. 7.)

The Autopilot programme has schemas or pages on:

- The Alphabet

- Letter names and sounds

- Blends

- Digraphs

- High Frequency words

The rote learning of the alphabet, numbers, days of the week and months of the year, are specific examples of verbal chaining, as the 'verbal chains are a sequence of successive, related simple facts’ (Kameenui \& Simmons, 1990 p71). Scott and Goetz (1978) researched rote learning and compared it with fun learning (game based learning) and found that those students who were trained with rote learning, what they call memorization procedures, demonstrated fewer errors than those using fun activities, when learning a verbal chain for example their phone number.

Tinkham (1989) researched attitudes to rote learning and noted, "despite its continuing unpopularity, rote learning remains a common activity in second language classrooms around the world” (p. 695). Tinkham advised curriculum developers, “ educators should take into consideration the strengths and attitudes of their students and take advantage of what those students bring to the classroom” (p. 697). Jensen (1974) undertook a large research project on digit span memory with grade four and five students. He found that rote learning was a successful strategy for this process

Repetition is seen by many researchers as an effective teaching practice for learning letter sounds and new words (Anderson et al., 1979). These researchers say that one of the twenty- two most effective principles of good teaching is, "The teacher should have the students repeat new words or sounds until they are said correctly” (p. 221). 
Many teachers struggle to find ways to help young students memorise the high frequency words for example (the, Here, Mother) that cannot be sounded out (Waring, 2001). Many use flash cards or contextual approaches. Waring found that rote learning was several times faster than learning from context.

\section{The Verbal Chaining Elements of Autopilot}

Mathematics - Counting in 1s, 2s, 5s, 10.

Fuson (1988) undertook a number of research projects involving counting skills with Grade 1-3 students. Fuson found that students who had the opportunity to practise counting skills, developed rote sequences that steadily increased. Without this rote practice, sequences did not improve. Fuson's research has been used as a starting point by many other researchers into students' counting skills. Rote counting to ten is a prerequisite to point counting or serial counting and finding the cardinal number of a set (Fuson et al., 1982; Fuson, 1988; Silbert \& Stein, 1981; Severson [undated]). Van Houten (1993) endorses Fuson's studies, “Basic number facts are typically taught by either rote or by counting set of objects" (p. 148). Those students who have the opportunity to practise the sequence are more likely to succeed (Baroody \& Price, 1983; Fuson, 1982; Smilkstein, 1993).

There are a number of key elements to mathematical rote learning sequences, these are; reinforcing that each number in the sequences should be a new number (Silbert \& Stein, 1981; Baroody \& Price, 1983), that students learn to count to ten before point counting to ten (Silbert \& Stein, 1981), that they say the number out loud and that they learn single digit sequences thoroughly before learning multi-digit sequences, as without an understanding of the single digit verbal chain, multi-digit counting (counting in 2 s, $5 \mathrm{~s} \& 10 \mathrm{~s}$ ) is restricted. The understanding of place-value is dependent on having a skill in multi-digit counting (Steffe \& Cobb, 1988).

Knowledge of the sequenced number terms provides the basis for symbolically representing quantities (Fazio, 1996, Fuson, 1988), “ - rote counting appears to be the bootstrap that allows one admission into the domain of numbers” (Carpenter \& Moser, 1984, p. 62). "In the earliest years of schooling, students' counting strategies 
are a clear indicator of their development in mathematics" (Davis, Pearn, Price \& Smith, 1997, p. 1).

New Zealand studies reinforce the need for verbal chaining of the number sequences, especially of rote counting and enumerating as the fundamental key to understanding number (Higgins, 1999). Higgins, a lecturer at the Wellington College of Education is adamant that understanding the counting sequences is the key to the understanding of mathematical concepts. She states, "The place of counting in place value understanding is well documented (Fuson, 1990; Kamii, 1985; Steffe \& Cobb, 1988),” (Higgins, 1999, p. 3).

Multi-digit counting is linked to "Times tables." Reciting the times-tables is one of the oldest rote learning practices. Severson (undated) believes that serial learning (rote learning) of times tables is a key to understanding number and emphasizes that paraprofessionals need to be trained in the delivery of rote practice. Recently a series of times tables audiotapes for New Zealand schools have been produced. These tapes (Adventure Maths -Times Tables), assist teachers to present the learning of the times tables in a fun way. The programme has the support of School Support Services, Ministry of Education, Wellington. A New Zealand newspaper article encouraged teachers and parents to assist students in the learning of times tables (Topliss, 1989). "Learning the times tables is like learning the basic words in a language,” says HOD of Maths Merv West of Dunedin Teachers College. "Its wider than Maths, its learning skills for life."

A number of authors have linked counting and reading (Davis, Pearn, Price \& Smith, 1997). The ability to unitize links the tasks. Being able to count and being able to recognise the phonemes within a word are similar strategies (Severson, undated).

Days of the Week \& Months of the Year

The Ministry of Education's Mathematics in the New Zealand Curriculum (1992) makes a clear statement that students at level 1 should be able to read aspects of time, including days of the week and months of the year. The days of the week / months of the year are verbal chains as they are a sequence of successive simple facts (Kameenui \& Simmons, 1990) and can easily be taught through direct instruction 
(Kameenui \& Simmons, 1990). They can also be taught with whole class model lead -test sequences as per Autopilot.

There is no logical reason for the sequencing of the successive simple facts of days / months into a chain and the only way many of the students can grasp the chain is through rote learning, first by learning “chunks” then combining the chunks into longer and longer sequences. There appears to be little research into the teaching the sequences of days of the months, months of the year, but as they are chains of simple facts (Kameenui \& Simmons, 1990) they should be treated the same way as other chains of simple facts, for example the alphabet and taught in chunks. Colarusso and O’Rourke (1999) in their guidelines on special education found that, an inability to recite the days of the week is an indication of learning disability. These students used the traditional approaches to learning the sequences.

\section{Phonological Awareness and Verbal Association}

A significant discovery about phonological development is that there is a striking relation between students' phonological skills and their readiness and success in reading (Bradley \& Bryant, 1983; Ball \& Blachman, 1988). Ball and Blachman’s research was based on a comparative study of two groups, one a phoneme segmentation group, a language activities group and a reading programme group. After seven weeks of instruction the phoneme segmentation group outperformed both other groups. Stanovick (1993-1994) defines phonological awareness as the ability to deal explicitly and segmentally with units smaller than a syllable. Adams (1990) argues that there are five levels of phonemic awareness beginning with the ability to hear rhymes and alliteration as measured by nursery rhymes, moving through contrasting and comparing sounds until at the highest level verbalizing sounds with letter names and blends.

Autopilot deals with a number of aspects of phonological awareness, reciting the alphabet, letter name recognition and naming and letter sound recognition and sounding.

A number of studies in the field of letter recognition and phonemic awareness, have found that training students to recognise letter names and sounds, at an early age (US 
Kindergarten level) significantly increased the students' ability to read at an earlier age and to spell more fluently (Bradley \& Bryant, 1983; Ball \& Blachman, 1988; Adams, 1990). Matching a name to a letter sound is one of the most important reading skills (Severson, undated; Samuels, 1970; Snell, 1993, Carnine et al., 1997). Decoding of new words cannot occur until students can decode by sounding out the letter sound alone (MacDonald, 1975; Kameenui \& Simmons, 1990).

Letter name learning is an associational process. It is associating verbal labels to a visual stimulus (Samuels, 1970) and is an important part of reading readiness (Samuels, 1970). Unfortunately not all students are able to distinguish letter names, even after a year of schooling and often still confuse p-b-d-q (Samuels, 1970). Bradley and Bryant (1983) researched the connection between failure in reading and a students' ability to categorise or hear sounds in words. They found that there is a definite relationship between a student's ability to categorise sounds and their eventual success in reading and spelling.

Learning letter names and letter sounds should be taught hand in hand. Ball and Blachman (1988) found that by just teaching letter names alone did not make any significant alteration to scores on letter sound recognition. Carnine et al., (1997) recommend that students learn sounds before names, but both must be learned. The Autopilot programme has all three elements covered on sequenced pages, alphabet reciting, letter-naming and letter-sound recognition.

The Autopilot programme appears to encompass a number of educational theories that may give pointers as to why teachers find it to be a useful classroom strategy. Not only are teachers expected to use successful strategies because the curriculum documents state that their use is compulsory, but they choose from a wide range of resources / programmes that meet their curriculum obligations. Autopilot is one such resource that is gaining favour. Before measuring its success or otherwise, we need to look at the educational theory of the information processing model, operant conditioning, schedules of reinforcement, direct instruction practices, the social constructivist model, scaffolded instruction and social learning theory and how it is linked to the processes of Autopilot. 
There are a number of processes that appear to be occurring during an Autopilot session. These are: reciting, rhymes and the rhythm of language, rehearsal, pointing, cuing, signalling, reinforcement, task enjoyment and modeling through peer mediated instruction, that is linked to social learning theory.

\section{Reciting, Rhymes and the Rhythm of Language.}

Reciting has a long educational history. It is the basis of learning tunes or "drama line” in drama / music classes. Many New Zealanders recall reciting or singing the times tables (Smilkstein, 1993) and having to learn a poem “off pat” by rote. Rote learning or reciting is the basis of traditional Maori whare waengana (a place where learning of whakapapa took place) (Smith 1913; Metge, 1990). Group responding or chanting still has its place in education. Group responding / reciting is the basis of the Oregon Direct Instruction Follow Through Program (Becker, 1977). This programme relies heavily on choral responses during a controlled practice phase. The

choral responses are specific responses to signals (Stevens \& Rosenshine, 1981). Becker (1977) found that choral responding was a successful strategy in a number of distinct ways. Choral responding allows a teacher to monitor the learning of all students effectively and quickly.

Reciting, rehearsal and rote learning are all linked processes. The process of repetitive rehearsal enhances the chance that information will be moved from short tom long-term memory. Gagné (1985) identified that information that is attended to (first stage), be passed on to the second stage, short-term memory, but storage is short and limited and is often lost unless it is rehearsed. Teachers should provide opportunities for over-learning through repetition and rehearsal (Clay, 1979).

Understanding the rhythm and nuances of the English language is a key ingredient to successful reading practice. Bradley and Bryant (1983) found that "students who are backward in reading are strikingly insensitive to rhyme and alliteration” (p. 419).

Adams (1990) found that there are five levels of phonemic awareness. The first level is the ability to hear rhymes and alliteration in nursery rhymes. Counting in 10s, where there is a repeated "ty" sound at the end of each number is an example of the 
simplicity of rhyme in number. The rhythm and rhyme in the reciting of the sequence of months is another excellent example of simple aural awareness.

Each chain, when recited has a natural "sing song" effect, very much like a tune. When reciting the verbal chain, students seem to grasp the lilt of the sequence before actually learning the individual elements. They will substitute "guesses" into the sequence, so that the rhythm is unaltered until they grasp the next chunk of the chain. Some chains are learned just like tunes or new songs. Understanding the rhyme and intonation of language is an important stepping-stone to reading success. Nursery rhymes have a similar "sing song", effect with young children (Danielson, 2000; Flett \& Conderman, 2002). The full version of Autopilot includes a weekly poem or rhyme that the children learn. These poems and rhymes are a favoured parts of the Autopilot programme and are rarely missed when a tutor selects pages for the day. The children seem to gain comfort from the familiarity of poetry sequences (Flett \& Conderman, 2002).

The Information Processing Model looks at how information is initially filtered, which causes some aspects of the information to be ignored and others to be attended to. The information that is attended to is then passed on to the second stage, shortterm memory. If the information is linked with prior knowledge, then the information is passed on to the long-term memory. Within the Autopilot programme the filtering process appears to be an attending issue. There is a heavy reliance on pointing, cuing and signalling.

\section{Pointing, Cuing and Signalling}

To ensure that the page is well paced, the Autopilot tutor points to each word ensuring that students are focused to the task and read it with the rhythm previously modeled by the teacher. "Teachers should not be afraid to encourage hand action to assist reading” (Clay, 1979, p. 61).

Teachers use cuing techniques to ensure that student attend to the task. When the students are confronted with a typical page of Autopilot for example "Days of the Week" the tutor begins by giving an aural cue; they say "Days of the Week." This focuses the student to task. The picture and the page itself is a visual cue. The 
students then chime in, having been aurally and visually cued, as the tutor points to each word, "Monday, Tuesday” and so forth.

The use of a pointer or pointing for early reading and number is well documented (Becker, 1977; Clay, 1979; Boyes, 2001) as it focuses the learner to the print (Boyes, 2001; Ministry of Education, 1996) and ensures that the rhythm of the language is emphasised (Leitch, 1996). The Ministry of Education in its guidelines for reading instruction, The Learner as a Reader (Ministry of Education, 1996) encourages teachers to use a pointer and cites it as one of the most effective ways of guiding students through enlarged text shared readers, (Autopilot is a large text shared reader). It is this rhythm of the verbal associations that seems to attract the students to the task.

The Reading Recovery programme (Clay, 1979) actively encourages students who are struggling with text, to use their fingers to help them focus to the text. The importance of developing a literacy set cannot be overlooked. The skills of: one to one correspondence, line to line sequence, word to word sequence, page to page sequence, first - last, beginning - end are all key elements in a pre-reading programme (Department of Education, 1985) and can be gained through following the cue of the pointer during Autopilot sessions.

Pointing is not specific to reading alone. Mathematics researchers also encourage active pointing. The use of touch and pointing helps reinforce what numbers are all about, a logical sequence that increase one by one (Baroody \& Price, 1983; Simpson, 1998). If teachers wish to use choral responding effectively, there needs to be a specific signal to initiate the response, (Stevens \& Rosenshine, 1981). The signal can either be, a pointer, an aural cue or a visual cue. "Choral responses are initiated by a specific signal from the teacher so that the entire group will respond at the same time (much like a conductor and an orchestra, and students are trained in this type of specific responding” (Stevens \& Rosenshine, 1981, p. 6). The Autopilot programme relies on two major prompts, aural / oral cuing and visual prompts.

The announcing of the title by the tutor, is an aural cue or signal. Anderson, Evertson and Brophy (1979) found that the use of a signal by a teacher (tutor) actively gained the students attention, saved time and helped students settle to the 
task. Aural / oral cuing and signals along the rhythm and lilt of the rote sequence are not the only systems that appear to keep students attending to the task. Students appear to be actively encouraged and reinforced from both the class teacher and the tutor.

\section{Reinforcement and Task Enjoyment}

The Autopilot programme appears to be maintained through operant conditioning (Skinner, 1938). The tutor praises compliance and may even select individual students to try and read the page themselves. An error prompts the rest of the class, led by the tutor to continue the page. The students respond positively by smiling, nodding or affirming the praise, regardless of whether it is the teacher or the tutor who gives the praise. A student who shows success and compliance is often rewarded, by being allowed to recite individually to the rest of the class. In terms of Skinner's operant behaviour, the students are more likely to contribute if they are positively praised and enjoy participating. The difference between rote learning and repetition revolves around intent and enjoyment of participation (Edwards, 2003). Edwards (2003) found with non-English speaking students (NESB), the key difference between rote learning and repetition was student intentions: whereas meaning did not feature in rote learning, it had an important place in repetition.

Operant conditioning (Cooper et al., 1987) occurs when the probability is determined by its history of consequences. Some students appear to be motivated by completing the task without error, others by guiding less able students and others by the chanting or the rhythm of the language.

Task enjoyment is a key component of the Autopilot programme. Schedules of reinforcement appear to help students sustain interest in the programme. Task persistence as well as enjoyment appear to be linked. Students are actively encouraged and reinforced to ensure that they stay on task and complete the sets of verbal chains.

Students appear to enjoy the familiarity of the daily sequences (Skinner, 1938; Cooper et al., 1987; Edwards, 2003). If the session is pleasurable, they are more likely to be drawn to the task (operant conditioning). It is unclear whether the 
enjoyment is from the familiarity of the pages or the rhyme of the language. Both seem to be significant to the successful completion of the verbal chains. McConkey and McEvoy (1986) found that if a task is simplified sufficiently so that students can experience success, then they gain confidence and are more willing to practice verbal sequences. Autopilot appears to be a non-threatening process, as participation in the tasks is voluntary. The tutors appear to be willing to guide others through the tasks, by praising participation and success.

The aim of the rote learning procedure of Autopilot fits with the informationprocessing model (Gagné, 1985). Daily practice is used to increase the length of the students' short-term memory sequences or verbal chains so that they become longterm memory. The usefulness of rote learning as a valid practice for increasing longterm memory has been widely debated.

Watkins, 2000, identified that memorising and understanding are linked. His study of Chinese students found that they spent much of their study time on repetition (rote learning) but used their study time in a group process supporting each other's learning. Chinese students are active learners, who view memorisation in a positive way.

\section{Modelling, Peer Mediated Instruction, Social Learning Theory and Calling on Students}

Autopilot relies heavily on modelling by a tutor who uses a pointer (usually a colourful wand) to focus the students. It is intended that the pointer focuses their attention and gives the correct pacing to the nature of the verbal chain being processed.

The process of "chiming in" forms part of most peer mediated instruction programmes (Limbrick, McNaughton \& Cameron, 1985). Active leading during reading instruction provides encouragement and the necessary modelling. The PausePrompt-Praise (McNaughton, Glynn \& Robinson, 1981) also uses active participation by the tutor to prompt correct responses. Peer mediated instruction programmes are well recognised in New Zealand education. The newly created positions of Resource Teachers: Literacy have a responsibility to up skill teachers in 
effective reading practice. One of the methods they advocate is peer-mediated instruction (Limbrick et al., 1985). The tutor leads and guides the tutee by scaffolding and prompting the text. Limbrick, McNaughton and Glynn (1985) found that not only do the tutees gain from the experience of being peer tutored, but the tutors also gain from the experience. Research programmes (Limbrick et al., 1985; Limbrick et al, 1985) have found that great gains can be made from well-structured tutoring programmes.

The direct instruction model (Kameenui \& Simmons, 1990) is usually used for the remediation of individual students on a one to one basis. This same strategy appears to apply to Autopilot, but with one major change. Autopilot is a whole class learning strategy. All students participate at the same time. The students follow the lead of the teacher or tutor, who models the correct serial sequence for example ABCDE. Students then recite along with the teacher / tutor repeating the sequence. The students are encouraged to try it themselves and the teacher / tutor assists or the whole class "chime in" if an error is made. This chime in process provides the modelling for the student who is trying the sequence for themselves, as well as other less confident students.

Stevens and Rosenshine (1981) in their examination of effective teaching practice identified key teaching practice strategies; one of these was group instruction. The NZCF identifies cooperative learning as a useful strategy. Peer mediated instruction falls within the realms of group instruction and cooperative learning. Peer mediated instruction is a powerful teaching strategy. It is an inclusive practice and meets the criteria of inclusive strategies that RTLB must model to class teachers.

For successful rote learning practice to occur in a school setting, the teacher needs to model the correct rate of verbalisation and scaffold students (Bliss \& Askew, 1996) through their initial attempts by using the Model - Lead - Check procedure (Kameenui \& Simmons, 1990). The initial rote learning sessions should be very precisely demonstrated through modeling, so that the students know "what you want them to do" (Frank, 1989, p. 15).

Calling on students appears to be a common practice in the Autopilot programme. It is used in varying degrees throughout the daily routine. The tutor selects students to 
lead a selected rote sequence or to contribute part of a sequence or verbal chain. This system is an integral and familiar part of the Autopilot programme. The "called on" student begins the sequence and is actively encouraged, by the tutor and the class through praise / acclamation, to continue to recite the sequence to the best of their ability. If the student falters, the rest of the class "chime in" and scaffold the sequence to its completion. The called on students are usually volunteers, but sometimes are selected for a specific task. The called on student does not risk failure in the task, as other students or the tutor will ensure the sequence is competed. This routine is repeated many times during the session. Calling on students is a way of assessing a student's ability on a task. Anderson, Evertson and Brophy (1979) found that calling on students (during controlled practice) was a most efficient assessment practice, whereas they found that calling on volunteers, random turns or callouts were all inefficient assessment tools.

\section{Training Tutors}

Two routines are used to train the tutors, “model, lead, test” (Kameenui \& Simmons, 1990) and scaffolded practice. The process of guiding and training students to take over as tutors follows a four-phase process.

1. Teacher Lead: Initially the teacher leads with all students following and participating in the session.

2. Modelling: The teacher leads and trainee tutor follows that lead and completes a page together that they are familiar with.

3. Scaffolding (Bliss \& Askew, 1996): The teacher acts as a guide and supports, by allowing the trainee tutor to work with guidance.

4. Independence: The tutor now takes over and works independently, but seeks advice from the teacher.

\section{Use of Autopilot}

This research study looks into whether Autopilot is a valid programme to increase or maintain understanding and knowledge of the verbal chains, by reciting the alphabet, counting sequences, days of the week and months of the year. The research also investigates the students' reaction to the programme and questions both students and teachers on their perceptions of the programme. 
Autopilot is widely used throughout Christchurch schools. It is used, not only as a teaching tool for increasing students knowledge and understanding of verbal chains and rote sequences, but is regarded by many as a useful tool in the maintenance of these concepts. Any Autopilot session will have students from a range of conceptual understanding and knowledge. Some students will be learning sequences, others will be adding or increasing their knowledge of chained sequences, others will be reinforcing and still others will be maintaining sequences. Those students who act as tutors will be maintaining their knowledge base. All will be at different levels on different chains. The importance of maintenance in the programme cannot be overlooked.

The curriculum states what is to be taught to students in their early years of New Zealand schooling. It does not state however, how schools and their teachers could design instruction. For some Christchurch teachers Autopilot is a useful tool in the preparation of students in the early stages of numeracy and literacy. As a learning tool it is based on sound learning theory, task selection and a tutor based instructional approach, where the tutors have been trained using modelled and scaffolded approaches.

Teachers consider that the use of verbal sequencing and chaining through the daily use of Autopilot, increases the students' knowledge of basic literacy and numeracy skills, as well as providing opportunities for a cooperative and inclusive approach to learning. 


\section{Chapter Three}

\section{Methodology}

The aim of this research was to investigate whether the use of the Autopilot programme in an Yr. 2 class was justified and whether the students were able to increase their knowledge of the verbal chains presented in the programme.

\section{Key Research Question}

Does a five week, 15 minutes per day whole class Autopilot programme, increase the Yr-2 students' knowledge of the alphabet, days of the week, months of the year and rote counting, for students who have not reached proficiency and maintain the levels for those students who have reached proficiency?

\section{Supplementary Questions}

Does the use of a five week, 15 minutes per day whole class Autopilot programme:

1. Increase the knowledge of discrete elements of the verbal chains: the alphabet, days of the week, months of the year and rote counting, when tested out of context?

2. Increase the length of the verbal chain after five weeks of daily instruction?

3. Result in the maintenance of the length of the verbal chain, after 5 weeks of discontinuation?

4. Increase the students' spontaneous use of the Autopilot charts as a resource during the class programme? For example, do they go to the charts when they need a word, sound etc. ?

5. Have benefits for the students' use of the knowledge in other curriculum areas? For example, do they use the knowledge of counting sequences during the normal Maths programme?

6. Lead to deeper understanding of the concepts used in the verbal-chains? For example, do students who have been exposed to reciting the alphabet have a greater understanding of letter sounds and names?

7. Lead to generalisation of the skills to other contexts?

8. Help students in their understanding of basic Maths / Language concepts? 


\section{Research design}

The research design was a quasi-experimental multiple baseline (Campbell \& Stanley, 1963). Two classes were involved in the research and each undertook the programme for five weeks. The researcher began tutoring class 1 on the first day of Term 2, 2003. Class 2 continued with their normal class programme. At the end of five weeks, both classes were reassessed using the original criteria. The researcher then repeated the tutoring with class 2; class 1 resumed their normal class programme, (without the use of Autopilot). At the end of the next five-week block, both classes were reassessed and the students were interviewed.

The assessments were looking for any statistical significance between the two classes, particularly whether the five weeks of Autopilot intervention, improved performance in the verbal chains compared to the five weeks of the regular programme. The assessments were also looking for any statistical significance relative to the maintenance of the verbal chains, five weeks after the completion of the programme.

In a quasi-experimental / multiple baseline research project, the researcher looks for cause-and-effect relationships, by using a pre - post design (Campbell \& Stanley, 1963). The reason behind the decision to use a quasi-experimental design was if one class were used, the researcher would not be able to have a control group and an experimental group in the same class.

To ensure that data were reliable and consistent the following processes were undertaken. The researcher trained both the teachers and the students from both classes in the use of Autopilot. All students from both classes were eligible for the research. The researcher approached all parents from the classes for approval to participate in the project. The project was part of an inclusive strategy used by the RTLB service in response to a syndicate referral by the syndicate leader, the teacher of Class 1. The researcher ensured that the introduction and presentation of Autopilot was consistent between the classes. Although Autopilot was a familiar part of the school programme, it was not introduced to the two research classes until the research began. At the conclusion of the ten-week period both students and teachers 
were interviewed, after their class programmes had returned to their normal routines.. The training was undertaken using scaffolded instruction (Wood, Bruner \& Ross, 1976).

The researcher had direct manipulation over of the independent variables by controlling the delivery of the programme, for example one class received a fiveweek block of Autopilot, whilst the other class did not. The groups were not equivalent, as they had different mixes of students, ages and so forth. The multiple baseline refers to the two-class approach, each beginning the research at different stages.

The following diagram (Figure 1.) shows the phases of the research.

Two weeks prior

Term 2

Data collection Both Classes
Term 1

Term 2
Week 1-5 Term 2

Class 1: Tutoring

Class 2: Regular

Programme

End of Week 5

Data Collection

Class 1 \& 2

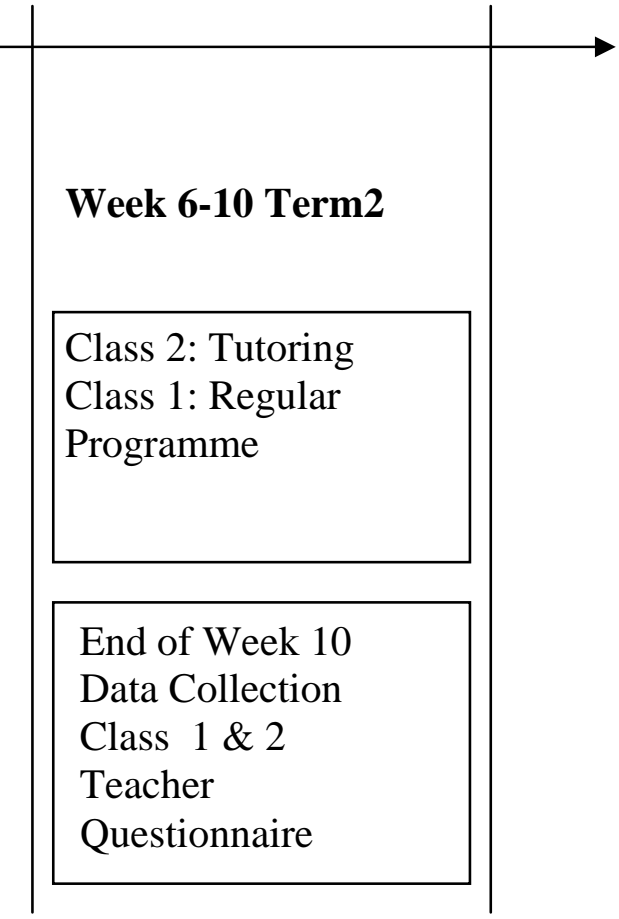

Figure 1

Phases of the research

\section{Setting}

The school selected was one of a number of schools using the Autopilot programme throughout the city. The school was a Decile 5 school with over 575 students. The school was a full primary school with 21 Yr. 1-8 classes. The school was fully 
inclusive, with all students being taught within the mainstream. The ethnic composition of the school population was:

83\% European

13\% Maori

2\% Other Pacific Island students

2\% Undesignated Asian or other ethnic groups

Girls 50\% Boys 50\%.

Class One had an ORRS (Ongoing Resource) student and a student with special needs on the autistic spectrum. The special needs students were included in the sample.

The school was familiar to the researcher who works as an RTLB in the school.

\section{Participants}

All students in the class had an opportunity to be part of the programme, as the introduction and teaching involved in the Autopilot programme, formed a normal part of the class programme. All parents were informed of the programme and the research and were asked if they wished their children to be included in the group for whom data were collected.

Prior to the research, the syndicate leader of Yr1-2 had indicated that she wished to introduce Autopilot into the class programmes of all four classes in her syndicate. As part of this RTLB referral all four classes had introductory sessions on Autopilot, but only two classes took part in the research.

The students taking part in the research were all volunteers. Two classes of Yr. 2 students were used. One class had twenty-four students (Class 1) the other twentythree (Class 2). Both classes were from the same school.

Class 1 had twenty-four students, four of whom were Maori (16\%). The class had thirteen boys and eleven girls ranging in age from (5.08 - 6.08 years). Class 2 had twenty-three students, two of whom were Maori (6\%). This class had ten boys and thirteen girls ranging in age from $(5.08-6.10$ years $)$. 
In Class 1, twelve students' parents gave permission for them to take part in the research, two of whom were Maori (16\%), there were six boys and six girls ranging in age from (5.08 - 6.07 years). Class 2 had fourteen students' parents gave permission for them to take part in the research, none of whom were Maori (0\%); there were seven boys and seven girls ranging in age from (5.08 - 6.06 years).

\section{Procedures}

Phase 1: Ethical Consent - Victoria University of Wellington, The Board of Trustees, Teachers, Parents and students.

Before any of the research was undertaken, approval for the project and the research was sought from the ethics committee at Victoria University of Wellington. The principal of the school was consulted and permission for the research was sought from the school's Board of Trustees (BOT). Once the BOT gave their consent, teachers, parents and students were consulted and consent was sought to take part in the research. A copy of the letter to the board is attached (Appendix C) as are the consent forms for teachers (Appendix D) and parents / students (Appendix E).

\section{Phase 2: Baseline Assessment (both classes)}

The twenty-six students from both classes who had consented to take part in the research were assessed using the same assessment procedures.

\section{Phase 3: Training in tutoring}

The researcher trained the class teachers of both classes in Autopilot procedures and supervised the training of the tutors.

\section{Phase 4: Tutoring with Class 1}

The researcher then began tutoring with Class 1 on the first day of Term 2, 2003. Class 2 continued with their normal class programme. At the end of five weeks, both classes were reassessed using the original criteria. Observations were also taken during this five-week period. An observation of the class programme of a class (Yr 2) not taking part in the Autopilot programme was also undertaken during week 1. 
The researcher then began tutoring with Class 2 on the first day of week 6 Term 2, 2003. Class 1 continued with their normal class programme (Autopilot had been removed from the class. Observations were also taken during this five-week period

\section{Phase 6: Both classes were reassessed}

At the end of the second five weeks, both classes were reassessed using the original criteria.

\section{Phase 7: Interviews were conducted}

At the end of the next five-week block, both classes were reassessed and the teachers and students completed the questionnaire.

\section{The regular class programme}

During the Autopilot programme intervention stage of five weeks in each class, the regular class programme continued. This class programme covered aspects of alphabet, counting, days of the week and months of the year. To ensure that the data were not biased, the class teachers agreed that although they were to cover aspects of the Autopilot elements, they would not undertake any rote teaching work other than in Autopilot. They have also agreed that the measurement elements of the Maths curriculum, that cover days and months would not be taught. Recognition of alphabet skills, phonemes etc. is a regular part of any class programme.

\section{Data Collection}

The researcher undertook the data collection. The recording sheets used for the data collection are described in instruments. The data collection was undertaken in accordance with the phases shown in Figure 1. The data was collected in a variety of ways, depending on the specific research question.

Supplementary Question 1 asked if there was any increase in the students' knowledge of discrete elements of the verbal chains: the alphabet, days of the week, months of the year and rote counting, when tested out of context? To ascertain this, a series of pre and post questions were set for the students and pre and post intervention data was collected. 


\section{Alphabet and Phoneme Knowledge}

As the students recited, the researcher scored on the record sheet (Appendix F).

a. Rote alphabet knowledge - to highest letter in order without error

i. Eg. ABCDEG

b. Letter names - from a sample list of 10 upper and lower case letters These letters were on prepared cards and the students were shown them one at a time

\section{i. K H B M Q R T O P F}

ii. $\mathrm{khbmqrtopf}$

c. Letter sounds - from sample list of 10 upper and lower case letters These sounds were on prepared cards and the students were shown them one at a time

i. Upper case: $\mathrm{V} Z \mathrm{Z} \mathrm{M} \mathrm{R}$ E $\mathrm{O} U \mathrm{X} \mathrm{Q}$ - the latter 5 being amongst the most to sound (Reading Recovery data). Reading Recovery data also shows that y is one of the most difficult sounds for students to recall, but three vowels are a sufficient in the sample).

ii. Lower case: $\mathrm{v} z \mathrm{z}$ t $\mathrm{r}$ e $\mathrm{o}$ u $\mathrm{x}$

\section{$\underline{\text { Rote Counting / Days and Months Serial Chains }}$}

As the students recited, the researcher scored on the record sheet (Appendix F).

1. Rote Counting in 1s, 2s, 5 s and 10s, to the highest without error

Eg. $123456 \underline{8} 910$ scores 6

Eg. $2468101214 \underline{17} 1820$ scores 7

2. Reciting the days of the week in sequence.

This will was modelled before testing began.

“ Listen carefully. I am going to tell you the days of the week.

Monday, Tuesday, Wednesday, Thursday, Friday, Saturday, Sunday

Now, I would like you to tell me the days of the week.”

The highest score possible was 7 .

Monday Tuesday Thursday Friday Saturday Sunday scores 2, although four are in sequence.

4. Reciting the months of the year in sequence.

This was modelled before testing began. 
“ Listen carefully. I am going to tell you the months of the year.

January, February, March, April, May, June, July, August, September,

October, November, December. Now, I would like you to tell me the

Months of the year.”

The highest score possible was 12 .

January, February, March, April, June, July, August, September,

October, November, December. scores 4, although 7 are in sequence.

Supplementary Questions 2 \& 3 were assessed using the same process as supplementary question 1 and were recorded on the record sheet (Appendix F).

Supplementary Question 4,

The researcher observed the students for one hour per week during Maths / Language instruction time and recorded instances of the spontaneous use of Autopilot. The instances were recorded in the form of anecdotal notes and tallied to see the overall use of Autopilot during class-time.

\section{Supplementary Question 5,}

The researcher surveyed the class teachers with a simple questionnaire, to ascertain whether or not, the students who had had daily instruction with Autopilot, used the knowledge gained in the appropriate curriculum areas. For example

1. "Has the daily use of Autopilot, aided phoneme understanding during written expression?” If the answer was yes, the researcher asked the teachers to give examples from their observations. The responses were collected on a questionnaire sheet (Appendix H reduced format). Other questions were:

2. Do students who have been exposed to Autopilot, spontaneously use it as a resource during the class programme? If yes, how?

3. Has Autopilot affected the class programme? If yes, how?

4. Do students who have had daily use of Autopilot; use the knowledge gained in the appropriate curriculum areas? If yes, give examples.

5. What types of learning occurs as a result of the introduction of Autopilot?

6. Does the use of Autopilot lead to deeper understanding of the concepts in the verbal-chains? If yes, give examples.

7. Are the concepts used in Autopilot generalised to other contexts? If yes, how? Give examples. 
The responses were summarised

Supplementary Question 6 \& 7,

The researcher sampled ten students' language books, prior to Autopilot, to ascertain whether or not they are able to spontaneously and correctly use any of the phonemes V Z M T R E O U X Q. This was compared with their spontaneous and correct use after instruction on Autopilot. Both classes used the Graves (Graves, 1983) approach to written language, where invented spelling was accepted as a first draft. The books were selected randomly - each student has a number on the class roll and the first ten odd numbers were selected.

Supplementary Question 8,

The researcher questioned students individually during their final assessment data collection session. The responses were recorded on a questionnaire sheet (Appendix $\mathrm{G}$ - reduced format)

The questions used were:

1. Tell me what you thought about Autopilot?

2. How has it helped you with you school work?

i. Supplementary Question. If yes - how?

3. What parts did you enjoy most?

i. Supplementary Question. What was the best part / parts you enjoyed the most?

4. Was it fun being a tutor / leader? If yes why?

5. What did you learn from Autopilot?

The responses were summarised

\section{Instruments}

Each class had the use of an Autopilot booklet designed by the Aranui RTLB service. It was in A3 format and consisted of 30 pages of which nine formed part of the research.

The researcher developed an assessment kit with flashcards for alphabet name testing.

A recording sheet (Appendix F) was designed to record data on the three assessment dates.

Observations were anecdotal and taken at the same time for both classes. 
The answers to both the student (Appendix G) and teacher (Appendix H) questions were recorded on a recording sheet

\section{Data Analysis}

Each of the key questions were analysed using the data collected from interviews, observations and the three assessments. Tables were produced to compare the effectiveness of each element (alphabet, months counting in fives and so forth). The data was analysed using a number of key criteria:

- Average change from the first to the second assessment and from the second to the third assessment. These assessments measured the length of the verbal chain or correct responses (in the cases of letter names and sounds).

- The average changes were compared for the same five-week period, between the class receiving the instruction and the class on the normal class programme. These were also compared when the roles were switched.

- Whether the change was an increase (positive change, designated with a +) a decrease (negative change, designated with a -) or no change (designated with a 0)

- The positive, negative or no changes were compared using a percentage formula.

- The potential for change was a key measure, as some students had reached the ceiling for that element during the instruction phase. Those students who had reached the ceiling were measured for maintenance of the chains and elements.

- The anecdotal data from the interviews were compared and summarised using a simple percentage for yes / no questions. Other responses were recorded and trends noted. Comments were recorded verbatim. 


\section{Chapter Four}

\section{Research Findings}

This chapter examines the findings of the research. It will consist of an examination of the research question and supplementary questions. Each of the elements, for example counting in 5s, will be examined separately and then compared with other rote sequences to assess trends. In this way a conclusion on the effectiveness or otherwise of the programme can be made.

The results and results tables are presented so that they show changes relating to two criteria; direction of change and percentage increase. It was decided to use these criteria for two reasons. Comparison between the length of the chains would be difficult, as their lengths varied considerably, for example the days of the week chain has only seven elements, whereas the counting in ones chain has one hundred elements. The second reason for using the criteria percentages and the direction of change, relates to the maximum score or ceiling effect, which was apparent in the results. In some assessments there were too few students who were able to make any potential change, as they had either reached the ceiling or maximum length of the chain and unable to make significant progress, or there were too few students in the class with the opportunity to make any potential change, to calculate statistical significance of the results.

The research question was:

Does a five week, 15 minutes per day whole class Autopilot programme, increase the Yr. 2 students' knowledge of the alphabet, days of the week, months of the year and rote counting, for students who have not reached proficiency and maintain the levels for those students who have reached proficiency?

\section{General conclusion}

The programme was more successful for the verbal chains of the alphabet and counting in $5 \mathrm{~s}$ and 10s. The use of Autopilot programme increased the individual letter name and sound (phonemic awareness) of the students, particularly the more difficult sounds of E U X and Q. Those students who used the programme made 
positive changes in the length of the verbal chain averaging $85.05 \%$. This compares to the average percentage increase for Class 2 with the regular programme of $39.5 \%$ (see Table 19). The verbal chains were maintained or had increased for all students in Class 1, who were reassessed five weeks after the programme concluded.

In all, seven verbal chains were researched, the alphabet, days of the week, months of the year, counting in 1s, 2s, $5 \mathrm{~s}$ and 10s. To ensure that learning the alphabet chain had some meaning, the letter names and letter sounds were examined in isolation to see if learning a chain had any affect on learning names and sounds. One of the pages presented in Autopilot had the letter names and sounds combined " $\mathrm{A}$ ah (a sound) apple, B bi (b sound) book” and so forth.

\section{Alphabet chain}

Eight out of nine students in Class 1 with a potential to change, who had the fiveweek Autopilot programme, showed an increase in the length of the chain with an average increase of 7.3 elements (see Table 1). This can be compared with the Class 2 who in the same time span ran the regular class programme. In this class, four out of 11 students with a potential to change, made improvements and their increase was only at 4.27 elements (see Table 2). When this class received Autopilot, seven out of eight students made improvements with an increase of 4.12 elements (see Table 2). The ceiling effect was noted here, as five out of the eight students were able to improve by only one element.

When first assessed, a number of students from both Class 1 and Class 2 began to sing the song when asked to recite the alphabet. For those students, the researcher modelled the correct response and asked them to repeat the process. Some continued with the song, albeit in a slowed down version. The first assessment results reflect this trend. Table 1 shows that of the nine students in class 1 , with the potential to change, eight did so after five weeks of instruction. All three students who had reached the maximum score (the ceiling) maintained it. When the programme was halted, one student continued to improve and all ten students who had reached the ceiling maintained it.

The average increase in the length of the chain was 7.3 elements. Three students scored twenty- five (the z was missed), all of these students said "zee” for "zed." 
This is common for students who sing the ABC song. Some students scored 11 or 12, again finding difficulty with L M N and singing "elem- en.” When the class was tutored to recite the alphabet, the teacher modelled a "snapped / tapped out" version that ensured the students recited one letter at a time.

Table 1

Number of correct responses of students in Class 1 and the direction of the change for the three assessments of the alphabet chain.

\begin{tabular}{|cccccccc|}
\hline Student & $1^{\text {st }}$ Assess & Change & $\begin{array}{c}\text { Sign } \\
\text { Change }\end{array}$ & $\begin{array}{c}2^{\text {nd }} \\
\text { Assess }\end{array}$ & Change & $\begin{array}{c}\text { Sign } \\
\text { Change }\end{array}$ & $\begin{array}{c}3^{\text {rd }} \\
\text { Assess }\end{array}$ \\
\hline $1 / 1$ & 19 & 6 & + & 25 & 1 & + & 26 \\
$1 / 2$ & 26 & 0 & & 26 & 0 & & 26 \\
$1 / 3$ & 21 & 5 & + & 26 & 0 & & 26 \\
$1 / 4$ & 4 & 22 & + & 26 & 0 & & 26 \\
$1 / 5$ & 11 & 15 & + & 26 & 0 & & 26 \\
$1 / 6$ & 4 & -1 & - & 3 & 0 & 0 & 3 \\
$1 / 7$ & 25 & 1 & + & 26 & 0 & & 26 \\
$1 / 8$ & 26 & 0 & & 26 & 0 & & 26 \\
$1 / 9$ & 25 & 1 & + & 26 & 0 & & 26 \\
$1 / 10$ & 23 & 3 & + & 26 & 0 & & 26 \\
$1 / 11$ & 12 & 14 & + & 26 & 0 & & 26 \\
$1 / 12$ & 26 & 0 & & 26 & 0 & & 26
\end{tabular}

Note $1:$ Maximum score $=26$

Note $2 \quad=$ No potential to change

Table 2

Class 2 continued with the regular class programme. Their improvement was less marked. The average increase was 4.27 elements (see Table 2) with only four out of the 11, with the potential to improve doing so. When Class 2 began to use the programme, they had equally positive results. Of the eight students who had the potential to change, seven did so, with an average increase of 4.12 elements. The spread of scores was limited by the maximum available mark, as there was a 'ceiling effect.' This ceiling effect limited the potential to change for five of the eight students, as there was only one element (z) that they could improve on. All of these students said "zee” for "zed.” None of the students repeated the error after five weeks of tutoring. Of the eight students who scored 11 or 12, (again having difficulty with L M N), all had corrected this after five weeks of tutoring. 
Table 2

Number of correct responses of students in Class 2 and the direction of the change for the three assessments of the alphabet verbal chain.

\begin{tabular}{|cccccccc|}
\hline Student & $\begin{array}{c}1^{\text {st }} \\
\text { Assess }\end{array}$ & Change & $\begin{array}{c}\text { Sign } \\
\text { Change }\end{array}$ & $\begin{array}{c}2^{\text {nd }} \\
\text { Assess }\end{array}$ & $\begin{array}{c}\text { Change } \\
\text { Change }\end{array}$ & $\begin{array}{c}3^{\text {rd }} \\
\text { Assess }\end{array}$ \\
\hline $1 / 1$ & 26 & 0 & & 26 & 0 & & 26 \\
$1 / 2$ & 26 & 0 & & 26 & 0 & & 26 \\
$1 / 3$ & 26 & 0 & & 26 & 0 & & 26 \\
$1 / 4$ & 25 & 0 & 0 & 25 & 1 & + & 26 \\
$1 / 5$ & 25 & 0 & 0 & 25 & 1 & + & 26 \\
$1 / 6$ & 25 & 0 & 0 & 25 & 1 & + & 26 \\
$1 / 7$ & 25 & 1 & + & 26 & 0 & & 26 \\
$1 / 8$ & 12 & 0 & 0 & 12 & 14 & + & 26 \\
$1 / 9$ & 12 & 13 & + & 25 & 1 & + & 26 \\
$1 / 10$ & 25 & 0 & 0 & 25 & 1 & + & 26 \\
$1 / 11$ & 12 & 0 & 0 & 12 & 14 & + & 26 \\
$1 / 12$ & 13 & 13 & + & 26 & 0 & & 26 \\
$1 / 13$ & 6 & 20 & + & 26 & 0 & & 26 \\
$1 / 14$ & 12 & 0 & 0 & 12 & 0 & 0 & 12
\end{tabular}

Note $1:$ Maximum score $=26$

Note $2 \quad=$ No potential to change

Months of the year.

Class 1 made a 39\% increase (see Table 3) in the length of the months of the year chain using Autopilot, compared to Class 2's 10\% increase with the regular class programme. Class 2 improved with Autopilot making a 65\% improvement (see Table 4), with all except one student reaching the ceiling.

The months of the year verbal chain has a particular appeal to students. They seem to respond to the rhythm of this sequence as if singing a song or reciting a poem. This was confirmed during classroom observations, where students who were not familiar with the sequence made up names of months to fit the rhythm pattern.

The first assessment showed that in Class 1 (see Table 3) seven of the 12 students had the potential to improve using Autopilot and an equal number (seven) had the potential to improve using the regular class programme. After five weeks of the intervention, six of the seven Class 1 students made improvements with an average change of 4.7 months, a 39\% increase in the length of the chain (see Table 3). 
Table 3

Number of correct responses of students in Class 1 and the direction of the change for the three assessments of the months of the year verbal chain.

\begin{tabular}{|c|c|c|c|c|c|c|c|}
\hline Student & $\begin{array}{c}1^{\mathrm{st}} \\
\text { Assess }\end{array}$ & Change & $\begin{array}{c}\text { Sign } \\
\text { Change }\end{array}$ & $\begin{array}{c}2^{\text {nd }} \\
\text { Assess }\end{array}$ & Change & $\begin{array}{c}\text { Sign } \\
\text { Change }\end{array}$ & $\begin{array}{c}3^{\text {rd }} \\
\text { Assess }\end{array}$ \\
\hline $1 / 1$ & 8 & 4 & + & 12 & - & & 12 \\
\hline $1 / 2$ & 12 & - & & 12 & - & & 12 \\
\hline $1 / 3$ & 1 & 11 & + & 12 & - & & 12 \\
\hline $1 / 4$ & 1 & 3 & + & 4 & 0 & 0 & 4 \\
\hline $1 / 5$ & 12 & - & & 12 & - & & 12 \\
\hline $1 / 6$ & 4 & 5 & + & 9 & 0 & 0 & 9 \\
\hline $1 / 7$ & 4 & 8 & + & 12 & - & & 12 \\
\hline $1 / 8$ & 12 & - & & 12 & - & & 12 \\
\hline $1 / 9$ & 2 & 2 & + & 4 & 5 & + & 9 \\
\hline $1 / 10$ & 12 & - & & 12 & - & & 12 \\
\hline $1 / 11$ & 12 & - & & 12 & - & & 12 \\
\hline $1 / 12$ & 9 & 0 & 0 & 9 & 0 & 0 & 9 \\
\hline
\end{tabular}

Note 1 : Maximum score $=12$

Note $2=$ No potential to change

Table 4

Number of correct responses of students in Class 2 and the direction of the change for the three assessments of the months of the year verbal chain.

\begin{tabular}{cccccccc|}
\hline Student & $\begin{array}{c}1^{\text {st }} \\
\text { Assess }\end{array}$ & Change & $\begin{array}{c}\text { Sign } \\
\text { Change }\end{array}$ & $\begin{array}{c}2^{\text {nd }} \\
\text { Assess }\end{array}$ & Change & $\begin{array}{c}\text { Sign } \\
\text { Change }\end{array}$ & $\begin{array}{c}3^{\text {rd }} \\
\text { Assess }\end{array}$ \\
\hline $1 / 1$ & 7 & 5 & + & 12 & - & & 12 \\
$1 / 2$ & 12 & - & & 12 & - & & 12 \\
$1 / 3$ & 12 & - & & 12 & - & & 12 \\
$1 / 4$ & 12 & - & & 12 & - & & 12 \\
$1 / 5$ & 12 & - & & 12 & - & & 12 \\
$1 / 6$ & 12 & - & & 12 & - & & 12 \\
$1 / 7$ & 1 & 3 & + & 4 & 0 & 0 & 4 \\
$1 / 8$ & 5 & 0 & 0 & 5 & 7 & + & 12 \\
$1 / 9$ & 1 & 0 & 0 & 1 & 11 & + & 12 \\
$1 / 10$ & 4 & 0 & 0 & 4 & 8 & + & 12 \\
$1 / 11$ & 3 & 0 & 0 & 3 & 9 & + & 12 \\
$1 / 12$ & 12 & - & & 12 & - & & 12 \\
$1 / 13$ & 12 & - & & 12 & - & & 12 \\
$1 / 14$ & 0 & 0 & 0 & 0 & 12 & + & 12
\end{tabular}

Note $1:$ Maximum score $=12$

Note $2=$ No potential to change

Of note in Table 4, 13 of the 14 students reached the ceiling at the completion of the intervention. No negative changes were observed with either of the classes, all students made either a positive or neutral change. 
Only two students from Class 2 made improvements with the regular class programme, with an average chain increase of 1.14, a 10\% improvement (see Table 4). However when Class 2 began their intervention in week 6, five of the six made improvements, with an average increase of 7.8 months, a 65\% increase. All students maintained the 12 months ceiling.

\section{Days of the week}

Both classes performed well in the assessments, with Class 1 having $100 \%$ success and Class 2 had 12 from 14 students gaining 100\%. With only two students from the twenty-six having any potential for improvement, the sample was too small to draw any valid conclusion, except that all maintained their $100 \%$ record on the second and third assessments.

\section{Rote Counting}

The rote counting chains had mixed success, depending on the length of the chain.

\section{Counting in 1s to 100}

In Class 1 seven students had the potential to make positive improvements with Autopilot after the initial assessment (Table 5). Of these, all made either a positive improvement or maintained their level with an average increase of 7.4. Of note four continued to improve once the programme had ceased with an even better improvement rate of 17.1 Seven students out of the 12 students failed to continue the chain after a nine (9) was said, for example 39 / 79, showing that there is a problem with naming the next ten in the sequence.

Class 2 continued to make improvements with the regular programme. The rate of improvement was six numbers in the chain. Their rate of improvement with Autopilot was 9.4 numbers (Table 6). Neither class made significant progress with Autopilot compared to the regular classroom programme. As with Class 1, Class 2 had problems with progressing from the 9 in a sequence with twelve out of nineteen errors noted with this digit. 
Table 5

Number of correct responses of students in Class 1 and the direction of the change for the three assessments of the counting in 1s verbal chain.

\begin{tabular}{cccccccc|}
\hline Student & $1^{\text {st }}$ Assess & Change & $\begin{array}{c}\text { Sign } \\
\text { Change }\end{array}$ & $\begin{array}{c}2^{\text {nd }} \\
\text { Assess }\end{array}$ & Change & $\begin{array}{c}\text { Sign } \\
\text { Change }\end{array}$ & $\begin{array}{c}3^{\text {rd }} \\
\text { Assess }\end{array}$ \\
\hline $1 / 1$ & 100 & - & & 100 & - & & 100 \\
$1 / 2$ & 100 & - & & 100 & - & & 100 \\
$1 / 3$ & 100 & - & & 100 & - & & 100 \\
$1 / 4$ & 39 & 20 & + & 59 & 41 & + & 100 \\
$1 / 5$ & 97 & 3 & + & 100 & 0 & & 100 \\
$1 / 6$ & 8 & 8 & + & 16 & 1 & + & 17 \\
$1 / 7$ & 79 & 0 & 0 & 79 & 21 & + & 100 \\
$1 / 8$ & 30 & 0 & 0 & 30 & -1 & - & 29 \\
$1 / 9$ & 100 & - & & 100 & - & & 100 \\
$1 / 10$ & 59 & 0 & 0 & 59 & 41 & + & 100 \\
$1 / 11$ & 79 & 21 & + & 100 & - & & 100 \\
$1 / 12$ & 100 & - & & 100 & - & & 100
\end{tabular}

Note $1:$ Maximum score $=100$

Note $2=$ No potential to change

Table 6

Number of correct responses of students in Class 2 and the direction of the change for the three assessments of the counting in 1s verbal chain.

\begin{tabular}{|c|c|c|c|c|c|c|c|}
\hline Pupil & $\begin{array}{c}1^{\text {st }} \\
\text { Assess }\end{array}$ & Change & $\begin{array}{l}\text { Sign } \\
\text { Change }\end{array}$ & $\begin{array}{c}2^{\text {nd }} \\
\text { Assess }\end{array}$ & Change & $\begin{array}{c}\text { Sign } \\
\text { Change }\end{array}$ & $\begin{array}{c}3^{\text {rd }} \\
\text { Assess }\end{array}$ \\
\hline $1 / 1$ & 59 & 0 & 0 & 59 & 0 & 0 & 59 \\
\hline $1 / 2$ & 100 & - & & 100 & & & 100 \\
\hline $1 / 3$ & 100 & - & & 100 & & & 100 \\
\hline $1 / 4$ & 89 & 0 & 0 & 89 & -4 & - & 85 \\
\hline $1 / 5$ & 79 & 21 & + & 100 & & & 100 \\
\hline $1 / 6$ & 59 & 34 & + & 93 & & + & 100 \\
\hline $1 / 7$ & 29 & -1 & - & 28 & 1 & + & 29 \\
\hline $1 / 8$ & 94 & 6 & + & 100 & & & 100 \\
\hline $1 / 9$ & 59 & 0 & 0 & 59 & 0 & 0 & 59 \\
\hline $1 / 10$ & 54 & 5 & + & 59 & 41 & + & 100 \\
\hline $1 / 11$ & 29 & 0 & 0 & 29 & 20 & + & 49 \\
\hline $1 / 12$ & 100 & - & & 100 & & & 100 \\
\hline $1 / 13$ & 28 & -6 & - & 22 & 7 & + & 29 \\
\hline $1 / 14$ & 12 & 7 & + & 19 & 20 & + & 39 \\
\hline
\end{tabular}

Note 1: Maximum score $=100$

Note $2 \quad=$ No potential to change 


\section{Counting in $2 \mathrm{~s}$}

Counting in 2s is an essential part of number study, particularly the understanding of even (and odd) numbers. Counting in 2s also forms part of students' playground chants, for example "2 468 who do we appreciate.” The research results on counting in $2 \mathrm{~s}$ is mixed.

Only one student in Class 1 had reached the ceiling at the first assessment. Eight made positive changes with an average increase of 5.1 elements, a $10 \%$ increase, however the increase was greater when the programme ceased with an average change of 8 elements, a 16\% increase (see Table 7).

Class 2 performed similarly, with no students having reached the ceiling before the intervention. However the increase with the intervention was more marked with this class. Ten positive changes, from a potential of fourteen occurred during the regular class programme. Twelve positive changes from a potential of fourteen occurred during the intervention. The element increase was 2.7 (5\%) with the regular class programme, but increased to 9.7 (20\%) with the intervention (see Table 8).

Table 7

Number of correct responses of students in Class 1 and the direction of the change for the three assessments of the counting in 2s verbal chain.

\begin{tabular}{cccccccc|}
\hline Student & $1^{\text {st }}$ Assess & Change & $\begin{array}{c}\text { Sign } \\
\text { Change }\end{array}$ & $\begin{array}{c}2^{\text {nd }} \\
\text { Assess }\end{array}$ & Change & $\begin{array}{c}\text { Sign } \\
\text { Change }\end{array}$ & $\begin{array}{c}3^{\text {rd }} \\
\text { Assess }\end{array}$ \\
\hline $1 / 1$ & 3 & 3 & + & 6 & 10 & + & 16 \\
$1 / 2$ & 50 & - & & 50 & - & & 50 \\
$1 / 3$ & 5 & 23 & + & 28 & 22 & + & 50 \\
$1 / 4$ & 6 & 1 & + & 7 & 7 & + & 14 \\
$1 / 5$ & 10 & 10 & + & 20 & 30 & + & 50 \\
$1 / 6$ & 3 & 0 & 0 & 3 & -1 & - & 2 \\
$1 / 7$ & 6 & 0 & 0 & 6 & 1 & + & 7 \\
$1 / 8$ & 6 & 1 & + & 7 & 7 & + & 14 \\
$1 / 9$ & 6 & 0 & 0 & 6 & -1 & - & 5 \\
$1 / 10$ & 0 & 4 & + & 4 & 9 & + & 13 \\
$1 / 11$ & 10 & 1 & + & 11 & -4 & - & 7 \\
$1 / 12$ & 37 & 13 & + & 50 & 0 & & 50
\end{tabular}

Note $1:$ Maximum score $=50$

Note $2 \quad=$ No potential to change 
Table 8

Number of correct responses of students in Class 2 and the direction of the change for the three assessments of the counting in 2 s verbal chain.

\begin{tabular}{cccccccc|}
\hline Student & $\begin{array}{c}1^{\text {st }} \\
\text { Assess }\end{array}$ & Change & $\begin{array}{c}\text { Sign } \\
\text { Change }\end{array}$ & $\begin{array}{c}2^{\text {nd }} \\
\text { Assess }\end{array}$ & $\begin{array}{c}\text { Change } \\
\text { Change }\end{array}$ & $\begin{array}{c}3^{\text {rd }} \\
\text { Assess }\end{array}$ \\
\hline $1 / 1$ & 7 & -1 & - & 6 & 10 & + & 16 \\
$1 / 2$ & 7 & 3 & + & 10 & 19 & + & 29 \\
$1 / 3$ & 1 & 5 & + & 6 & 10 & + & 16 \\
$1 / 4$ & 1 & 5 & + & 6 & 0 & 0 & 6 \\
$1 / 5$ & 5 & 9 & + & 14 & 3 & + & 17 \\
$1 / 6$ & 5 & 4 & + & 9 & 11 & + & 20 \\
$1 / 7$ & 4 & 2 & + & 6 & 0 & 0 & 6 \\
$1 / 8$ & 4 & 3 & + & 7 & 43 & + & 50 \\
$1 / 9$ & 6 & -5 & - & 1 & 5 & + & 6 \\
$1 / 10$ & 1 & 1 & + & 2 & 4 & + & 6 \\
$1 / 11$ & 6 & 3 & + & 9 & 15 & + & 24 \\
$1 / 12$ & 1 & 9 & + & 10 & 1 & + & 11 \\
$1 / 13$ & 0 & 0 & 0 & 0 & 14 & + & 14 \\
$1 / 14$ & 0 & 0 & 0 & 0 & 1 & + & 1
\end{tabular}

Note $1:$ Maximum score $=50$

Note $2=$ No potential to change

Counting in 5s to 100

Improvements were made when both classes used Autopilot. The children themselves identified counting in 5 s as one of their favourite Autopilot activities and observations showed that students warmed to this task with its particular rhythm pattern. When observing the classes it appeared to the researcher that they seemed to lift themselves for this task and increase their participation level, with some even tapping out the rhythm or slapping their knees. In Class 1 nine of the 11 students with the potential to make positive changes, made an average increase of 12 elements, a 60\% improvement (see Table 9). Before the intervention, only one student had reached the ceiling. Five weeks later seven students had reached the ceiling. This was maintained after the programme ceased with 11 out of the 12 students maintaining or increasing their scores with a 3.4 (17\%) element increase. 
Table 9

Number of correct responses of students in Class 1 and the direction of the change for the three assessments of the counting in 5 s verbal chain.

\begin{tabular}{|c|c|c|c|c|c|c|c|}
\hline Student & $\begin{array}{c}1^{\text {st }} \\
\text { Assess }\end{array}$ & Change & $\begin{array}{l}\text { Sign } \\
\text { Change }\end{array}$ & $\begin{array}{c}2^{\text {nd }} \\
\text { Assess }\end{array}$ & Change & $\begin{array}{c}\text { Sign } \\
\text { Change }\end{array}$ & $\begin{array}{c}3^{\text {rd }} \\
\text { Assess }\end{array}$ \\
\hline $1 / 1$ & 1 & 19 & + & 20 & - & & 20 \\
\hline $1 / 2$ & 20 & - & & 20 & - & & 20 \\
\hline $1 / 3$ & 4 & 16 & + & 20 & - & & 20 \\
\hline $1 / 4$ & 4 & 15 & + & 19 & -10 & - & 9 \\
\hline $1 / 5$ & 3 & 17 & + & 20 & - & & 20 \\
\hline $1 / 6$ & 4 & 0 & 0 & 4 & 0 & 0 & 4 \\
\hline $1 / 7$ & 5 & 5 & + & 10 & 3 & + & 13 \\
\hline $1 / 8$ & 0 & 20 & + & 20 & - & & 20 \\
\hline $1 / 9$ & 1 & 1 & + & 2 & 8 & + & 10 \\
\hline $1 / 10$ & 1 & 19 & + & 20 & - & & 20 \\
\hline $1 / 11$ & 9 & -5 & - & 4 & 16 & + & 20 \\
\hline $1 / 12$ & 0 & 20 & + & 20 & - & & 20 \\
\hline
\end{tabular}

Note 1 : Maximum score $=20$

Note $2=$ No potential to change

Table 10

Number of correct responses of students in Class 2 and the direction of the change for the three assessments of the counting in 5 s verbal chain.

\begin{tabular}{|crrrrrrr|}
\hline & $1^{1^{\text {st }}}$. & & Sign & $2^{\text {nd }}$ & & Sign & $3^{\text {rd }}$ \\
Student & Assess & Change & Change & Assess & Change & Change & Assess \\
\hline $1 / 1$ & 1 & 19 & + & 20 & - & \\
$1 / 2$ & 20 & - & & 20 & - & 20 \\
$1 / 3$ & 2 & 1 & + & 3 & 17 & + & 20 \\
$1 / 4$ & 2 & -2 & - & 0 & 20 & + & 20 \\
$1 / 5$ & 2 & 0 & 0 & 2 & 18 & + & 20 \\
$1 / 6$ & 1 & 1 & + & 2 & 18 & + & 20 \\
$1 / 7$ & 0 & 0 & 0 & 0 & 20 & + & 20 \\
$1 / 8$ & 2 & 18 & + & 20 & - & & 20 \\
$1 / 9$ & 2 & -1 & - & 1 & 19 & + & 20 \\
$1 / 10$ & 2 & 0 & 0 & 2 & 18 & + & 20 \\
$1 / 11$ & 2 & 0 & 0 & 2 & 18 & + & 20 \\
$1 / 12$ & 1 & -1 & - & 0 & 17 & + & 17 \\
$1 / 13$ & 2 & -2 & 0 & 0 & 20 & + & 20 \\
$1 / 14$ & 0 & 0 & 0 & 0 & 3 & + & 3
\end{tabular}

Note 1 : Maximum score $=20$

Note $2=$ No potential to change 
Class 2 (see Table 10) continued their regular classroom programme with an average element increase of 2.5 (12.5\%). But after five weeks of the intervention, their increase was even more pronounced with a 17-element increase (85\%). Before the intervention, three of the 14 students had reached the ceiling, after the intervention, twelve had reached the ceiling.

\section{Counting in 10 s to 100}

Counting in 10s has a distinctive rhythm, especially from 30 onwards that appeals to students. In Class 1 (Table 11), five students had not reached the ceiling at the first assessment. After five weeks of Autopilot, all five students had made a positive increase with three of these students reaching the ceiling with an average increase of 3.4 or $28 \%$.

This compares with Class 2 (Table 12) who over the same five-week period had only one student make a positive change with the regular class programme. The average increase for this class was .2 or a $2 \%$ increase. However on assessment three, after five weeks of the programme, their average increase was 6.5. or $65 \%$ increase.

Table 11

Number of correct responses of students in Class 1 and the direction of the change for the three assessments of the counting in 10s verbal chain.

\begin{tabular}{|cccccccc|}
\hline Student & $1^{\text {st }}$ Assess & Change & $\begin{array}{c}\text { Sign } \\
\text { Change }\end{array}$ & $\begin{array}{c}2^{\text {nd }} \\
\text { Assess }\end{array}$ & Change & $\begin{array}{c}\text { Sign } \\
\text { Change }\end{array}$ & $\begin{array}{c}3^{\text {rd }} \\
\text { Assess }\end{array}$ \\
\hline $1 / 1$ & 9 & 1 & + & 10 & - & & 10 \\
$1 / 2$ & 10 & - & & 10 & - & & 10 \\
$1 / 3$ & 10 & - & & 10 & - & & 10 \\
$1 / 4$ & 10 & - & & 10 & - & & 10 \\
$1 / 5$ & 10 & - & & 10 & - & & 10 \\
$1 / 6$ & 3 & 4 & + & 7 & -2 & - & 5 \\
$1 / 7$ & 9 & 1 & + & 10 & - & & 10 \\
$1 / 8$ & 10 & - & & 10 & - & & 10 \\
$1 / 9$ & 3 & 2 & + & 5 & 5 & + & 10 \\
$1 / 10$ & 1 & 9 & + & 10 & - & & 10 \\
$1 / 11$ & 10 & - & & 10 & - & & 10 \\
$1 / 12$ & 10 & - & & 10 & - & & 10
\end{tabular}

Note $1:$ Maximum score $=10$

Note $2=$ No potential to change 
Table 12

Number of correct responses of students in Class 2 and the direction of the change for the three assessments of the counting in 10s verbal chain.

\begin{tabular}{|c|c|c|c|c|c|c|c|}
\hline Student & $\begin{array}{c}1^{\text {st }} \\
\text { Assess }\end{array}$ & Change & $\begin{array}{c}\text { Sign } \\
\text { Change }\end{array}$ & $\begin{array}{c}2^{\text {nd }} \\
\text { Assess }\end{array}$ & Change & $\begin{array}{c}\text { Sign } \\
\text { Change }\end{array}$ & $\begin{array}{c}3^{\text {rd }} \\
\text { Assess }\end{array}$ \\
\hline $1 / 1$ & 9 & 1 & + & 10 & - & & 10 \\
\hline $1 / 2$ & 10 & - & & 10 & - & & 10 \\
\hline $1 / 3$ & 10 & - & & 10 & - & & 10 \\
\hline $1 / 4$ & 10 & - & & 10 & - & & 10 \\
\hline $1 / 5$ & 10 & - & & 10 & - & & 10 \\
\hline $1 / 6$ & 10 & - & & 10 & - & & 10 \\
\hline $1 / 7$ & 0 & 0 & 0 & 0 & 10 & + & 10 \\
\hline $1 / 8$ & 10 & - & & 10 & - & & 10 \\
\hline $1 / 9$ & 1 & 0 & 0 & 1 & 8 & + & 9 \\
\hline $1 / 10$ & 10 & - & & 10 & - & & 10 \\
\hline $1 / 11$ & 10 & - & & 10 & - & & 10 \\
\hline $1 / 12$ & 10 & - & & 10 & - & & 10 \\
\hline $1 / 13$ & 1 & 0 & 0 & 1 & 8 & + & 9 \\
\hline $1 / 14$ & 1 & 0 & 0 & 1 & 0 & 0 & 1 \\
\hline
\end{tabular}

Note 1 : Maximum score $=10$

Note $2 \quad=$ No potential to change

\section{Supplementary Question 1}

Does the use of a five week, 15 minutes per day whole class Autopilot programme increase the knowledge of discrete elements of the verbal chains: the alphabet, days of the week, months of the year and rote counting, when tested out of context?

Only the knowledge of letter names and letter sounds were tested out of context. The results of these are shown in Tables 13 to 18, where it was found that Autopilot increased the knowledge of individual letters, particularly those commonly missounded letters E U X and Q

\section{Letter names and sounds}

All students in Class 1 made improvements with their letter names (see Table 13).

However, before Autopilot, no students in Class 1 were able to correctly sound the 20 nominated letter sounds, but after five weeks of Autopilot six had a 100\% score, with an average increase of 4.1 letters, a 20\% increase (see Table 15). 
Table 13

Number of correct responses of students in Class 1 and the direction of the change for the three assessments of the twenty selected letter names.

\begin{tabular}{|cccccccc|}
\hline Student & $1^{\text {st }}$ Assess & Change & $\begin{array}{c}\text { Sign } \\
\text { Change }\end{array}$ & $\begin{array}{c}2^{\text {nd }} \\
\text { Assess }\end{array}$ & Change & $\begin{array}{c}\text { Sign } \\
\text { Change }\end{array}$ & $\begin{array}{c}3^{\text {rd }} \\
\text { Assess }\end{array}$ \\
\hline $1 / 1$ & 19 & 1 & + & 20 & - & 20 \\
$1 / 2$ & 20 & - & & 20 & - & 20 \\
$1 / 3$ & 20 & - & & 20 & - & 20 \\
$1 / 4$ & 20 & - & & 20 & - & 20 \\
$1 / 5$ & 20 & - & & 20 & - & 20 \\
$1 / 6$ & 13 & 7 & + & 20 & - & 20 \\
$1 / 7$ & 19 & 1 & + & 20 & - & 20 \\
$1 / 8$ & 20 & - & & 20 & - & 20 \\
$1 / 9$ & 20 & - & & 20 & - & 20 \\
$1 / 10$ & 20 & - & & 20 & - & \\
$1 / 11$ & 20 & - & & 20 & - & \\
$1 / 12$ & 20 & - & & 20 & - & & 20 \\
\hline
\end{tabular}

Note 1 : Maximum score $=20$

Note $2=$ No potential to change

Table 14

Number of correct responses of students in Class 2 and the direction of the change for the three assessments of the twenty selected letter names.

\begin{tabular}{|c|c|c|c|c|c|c|c|}
\hline Student & $\begin{array}{c}1^{\mathrm{st}} \cdot \\
\text { Assess }\end{array}$ & Change & $\begin{array}{c}\text { Sign } \\
\text { Change }\end{array}$ & $\begin{array}{c}2^{\text {nd }} \\
\text { Assess }\end{array}$ & Change & $\begin{array}{c}\text { Sign } \\
\text { Change }\end{array}$ & $\begin{array}{c}3^{\text {rd }} \\
\text { Assess }\end{array}$ \\
\hline $1 / 1$ & 20 & & & 20 & & & 20 \\
\hline $1 / 2$ & 20 & & & 20 & & & 20 \\
\hline $1 / 3$ & 20 & & & 20 & & & 20 \\
\hline $1 / 4$ & 20 & & & 20 & & & 20 \\
\hline $1 / 5$ & 19 & 1 & + & 20 & & & 20 \\
\hline $1 / 6$ & 20 & & & 20 & & & 20 \\
\hline $1 / 7$ & 20 & & & 20 & & & 20 \\
\hline $1 / 8$ & 20 & & & 20 & & & 20 \\
\hline $1 / 9$ & 20 & & & 20 & & & 20 \\
\hline $1 / 10$ & 20 & & & 20 & & & 20 \\
\hline $1 / 11$ & 20 & & & 20 & & & 20 \\
\hline $1 / 12$ & 20 & & & 20 & & & 20 \\
\hline $1 / 13$ & 20 & & & 20 & & & 20 \\
\hline $1 / 14$ & 20 & & & 20 & & & 20 \\
\hline
\end{tabular}

Note 1 : Maximum score $=20$

Note $2=$ No potential to change 
This compares to Class 2 who in the same time span experienced the regular class programme. All fourteen had reached the ceiling for letter names before the intervention took place (see Table 14).

In Class 2 only one student had not reached the ceiling on the first assessment, but had did so before the programme began. All maintained the ceiling after the programme had been completed (see Table 15).

\section{Table 15}

Number of correct responses of students in Class 1 and the direction of the change for the three assessments of twenty letter sounds.

\begin{tabular}{|rccccccc|}
\hline Student & $1^{\text {st }}$ Assess & Change & $\begin{array}{c}\text { Sign } \\
\text { Change }\end{array}$ & $\begin{array}{c}2^{\text {nd }} \\
\text { Assess }\end{array}$ & Change & $\begin{array}{c}\text { Sign } \\
\text { Change }\end{array}$ & $\begin{array}{c}3^{\text {rd }} \\
\text { Assess }\end{array}$ \\
\hline $1 / 1$ & 18 & 2 & + & 20 & 0 & & 20 \\
$1 / 2$ & 17 & 3 & + & 20 & 0 & & 20 \\
$1 / 3$ & 12 & 6 & + & 18 & 2 & + & 20 \\
$1 / 4$ & 16 & 1 & + & 17 & 3 & + & 20 \\
$1 / 5$ & 18 & 2 & + & 20 & 0 & & 20 \\
$1 / 6$ & 2 & 5 & + & 7 & 4 & + & 11 \\
$1 / 7$ & 16 & 4 & + & 20 & 0 & & 20 \\
$1 / 8$ & 16 & 2 & + & 18 & 1 & + & 19 \\
$1 / 9$ & 11 & 8 & + & 19 & 0 & 0 & 19 \\
$1 / 10$ & 12 & 1 & + & 13 & 1 & + & 14 \\
$1 / 11$ & 16 & 4 & + & 20 & 0 & & 20 \\
$1 / 12$ & 9 & 11 & + & 20 & 0 & & 20
\end{tabular}

Note 1 : Maximum score $=20$

Note $2 \quad=$ No potential to change 
Table 16

Number of correct responses of students in Class 2 and the direction of the change for the three assessments of twenty letter sounds.

\begin{tabular}{|cccccccc|}
\hline Student & $\begin{array}{c}1^{\text {st }} \\
\text { Assess }\end{array}$ & Change & $\begin{array}{c}\text { Sign } \\
\text { Change }\end{array}$ & $\begin{array}{c}2^{\text {nd }} \\
\text { Assess }\end{array}$ & $\begin{array}{c}\text { Change } \\
\text { Change }\end{array}$ & $\begin{array}{c}3^{\text {rd }} \\
\text { Assess }\end{array}$ \\
\hline $1 / 1$ & 20 & 0 & & 20 & 0 & & 20 \\
$1 / 2$ & 20 & 0 & & 20 & 0 & & 20 \\
$1 / 3$ & 20 & 0 & & 20 & 0 & & 20 \\
$1 / 4$ & 18 & 0 & 0 & 18 & 2 & + & 20 \\
$1 / 5$ & 19 & 1 & + & 20 & 0 & & 20 \\
$1 / 6$ & 16 & 2 & + & 18 & 2 & + & 20 \\
$1 / 7$ & 13 & 3 & + & 16 & 4 & + & 20 \\
$1 / 8$ & 13 & 0 & 0 & 13 & 7 & + & 20 \\
$1 / 9$ & 12 & 0 & 0 & 12 & 6 & + & 18 \\
$1 / 10$ & 16 & 0 & 0 & 16 & 2 & + & 18 \\
$1 / 11$ & 15 & 0 & 0 & 15 & 3 & + & 18 \\
$1 / 12$ & 13 & -2 & - & 11 & 3 & + & 14 \\
$1 / 13$ & 18 & 0 & 0 & 18 & 2 & + & 20 \\
$1 / 14$ & 13 & -1 & - & 12 & 4 & + & 16
\end{tabular}

Note 1 : Maximum score $=20$

Note $2=$ No potential to change

Ten letter names and sounds were selected with the support of a Reading Recovery (Clay, 1979) tutor. The letter names K H B M Q R T O P F were tested in random order. Of the ten letter sounds, five were regular and familiar sounds, $M T R$ Z O and five others were the most commonly mispronounced sounds - : E V U X Q $\mathrm{V}$ was quickly eliminated from further specific assessment, as both classes did not have problems with this letter.

Four particular letter sounds were isolated for further investigation E U X and Q. These sounds were found by both classes to be the most difficult. When each class received the Autopilot programme they made a significant improvements in the sounding of these letters. Before Autopilot was introduced, the highest average score for the class was 58\% correct for the letter E with an overall average correct percentage of $41.5 \%$ correct. This improved to $74.75 \%$ after five weeks of Autopilot instruction and was maintained and improved to $84 \%$ five weeks later (see Table 17). Of particular note, the letter sound for $\mathrm{u}$, had the lowest percentage score, but made the greatest improvement from 16\% to 83\%. This compares with Class 2 who continued with the regular class programme in the same time span and made an 
increase of $8 \%$, then with the programme went from $61 \%$ to $83 \%$ correct (see Table 18).

Table 17

Percentage of correct responses for the four most difficult letter sounds Ee Uu Xx Qq for Class 1 taken over three assessments.

\begin{tabular}{lrcc|}
\hline Letter Sounds & \multicolumn{2}{c}{$\begin{array}{c}\text { First Assessment } \\
\text { Class 1 }\end{array}$} & \multicolumn{2}{c|}{$\begin{array}{c}\text { Second Assessment } \\
\text { Class 1 }\end{array}$} & $\begin{array}{c}\text { Third Assessment } \\
\text { Class 1 }\end{array}$ \\
\hline E & $58 \%$ & $75 \%$ & $83 \%$ \\
$\mathrm{U}$ & $41 \%$ & $75 \%$ & $83 \%$ \\
$\mathrm{X}$ & $41 \%$ & $66 \%$ & $83 \%$ \\
$\mathrm{Q}$ & $58 \%$ & $91 \%$ & $91 \%$ \\
$\mathrm{e}$ & $41 \%$ & $75 \%$ & $83 \%$ \\
$\mathrm{u}$ & $16 \%$ & $83 \%$ & $83 \%$ \\
$\mathrm{x}$ & $25 \%$ & $58 \%$ & $83 \%$ \\
$\mathrm{q}$ & $50 \%$ & $75 \%$ & $83 \%$
\end{tabular}

Average Percentage
Score
$41.5 \%$
$74.75 \%$
$84 \%$

Table 18

Percentage of correct responses for the four most difficult letter sounds Ee Uu Xx Qq for Class 2 taken over three assessments.

\begin{tabular}{lrcc|}
\hline Letter Sounds & $\begin{array}{c}\text { First Assessment } \\
\text { Class 2 }\end{array}$ & $\begin{array}{c}\text { Second Assessment } \\
\text { Class 2 }\end{array}$ & $\begin{array}{c}\text { Third Assessment } \\
\text { Class 2 }\end{array}$ \\
\hline $\mathrm{E}$ & $57 \%$ & $64 \%$ & $92 \%$ \\
$\mathrm{U}$ & $64 \%$ & $71 \%$ & $85 \%$ \\
$\mathrm{X}$ & $35 \%$ & $42 \%$ & $71 \%$ \\
$\mathrm{Q}$ & $78 \%$ & $78 \%$ & $78 \%$ \\
$\mathrm{e}$ & $42 \%$ & $57 \%$ & $92 \%$ \\
$\mathrm{u}$ & $50 \%$ & $57 \%$ & $85 \%$ \\
$\mathrm{X}$ & $35 \%$ & $50 \%$ & $78 \%$ \\
$\mathrm{q}$ & $64 \%$ & $71 \%$ & $85 \%$ \\
Average Percentage & & & $83.25 \%$ \\
Score & $53.12 \%$ & $61.25 \%$ &
\end{tabular}


Figure 2 shows the letter sound comparisons for Class 1. Class 2 did not make any significant improvement with the four most difficult letter sounds (Table 18) until they received Autopilot instruction with the average increasing from $61.25 \%$ to 83.25\% (See Figure 3)

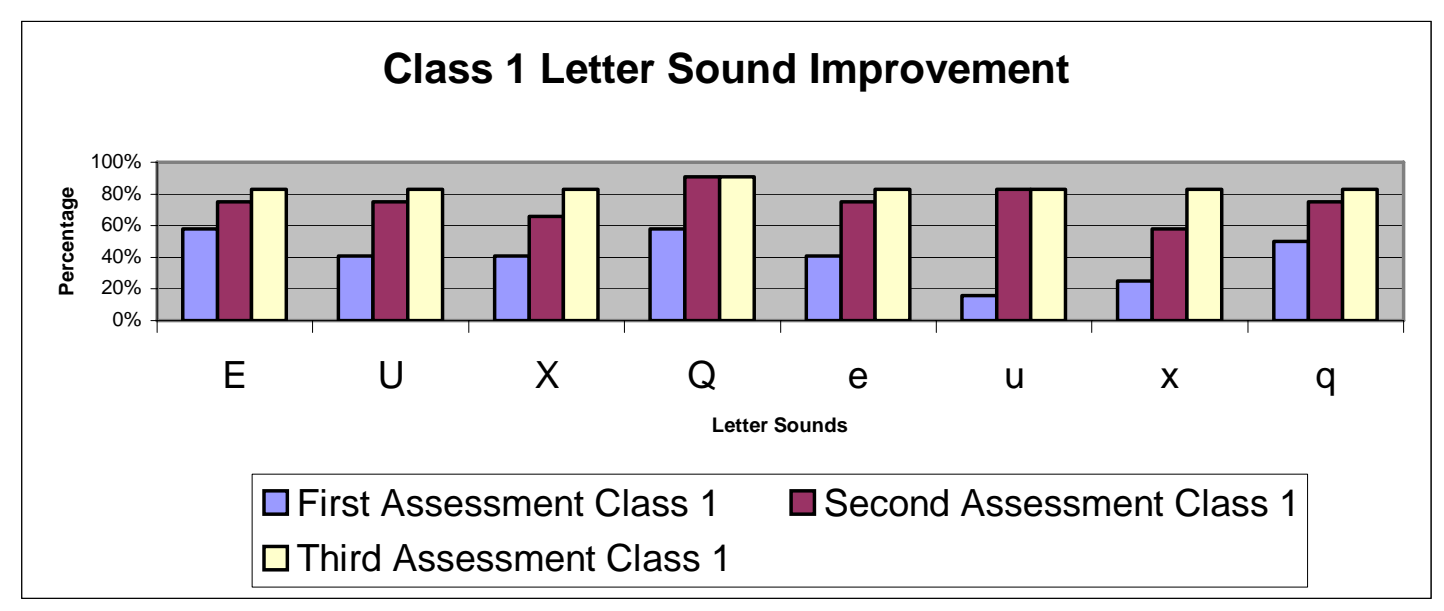

Figure 2

Percentage of correct responses for Class 1 of letter sounds E U X \& Q for three assessments.

NB: $\square$ The second assessment was taken after the completion of five weeks of Autopilot.

The individual percentage increases for each letter are shown on Figure 3

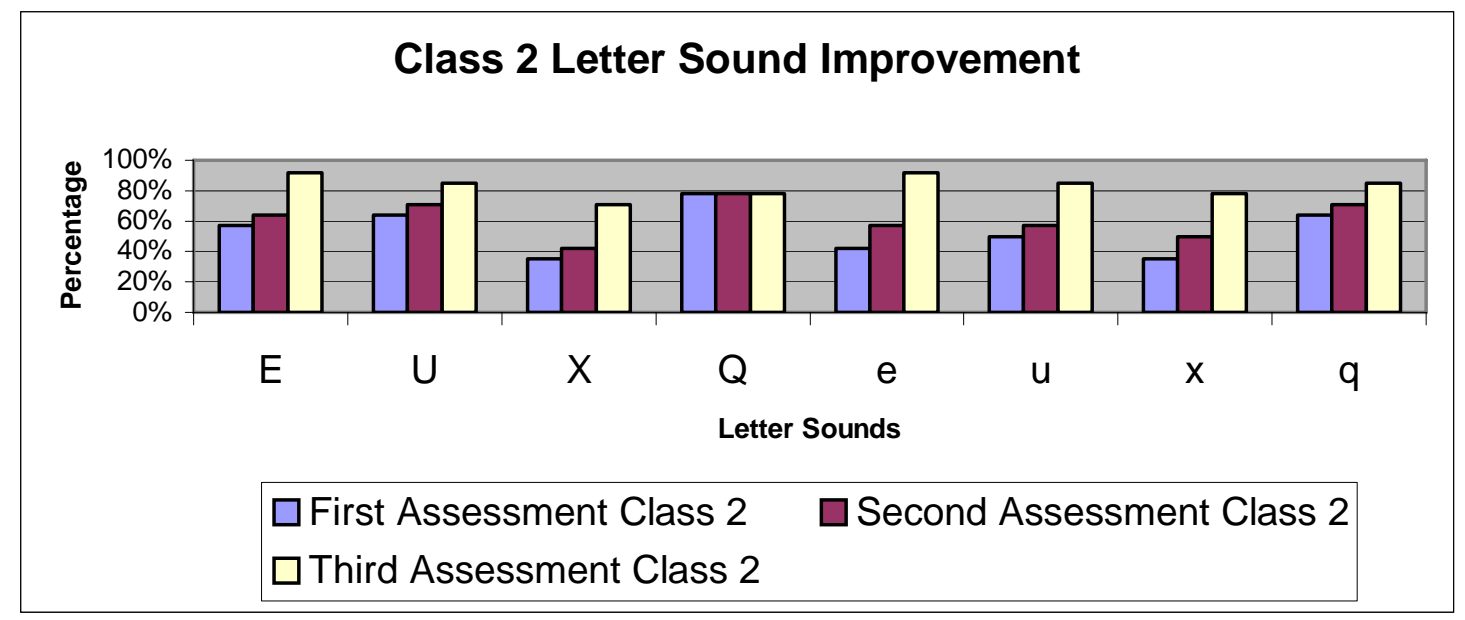

Figure 3

Percentage comparison for Class 2 of letter sounds E U X \& Q for three assessments.

NB: $\square$ The third assessment was taken after the completion of five weeks of Autopilot. 


\section{Supplementary Question 2}

Does the use of a five week, 15 minutes per day whole class Autopilot programme increase the length of the verbal chain after five weeks of daily instruction?

In all cases the length of the chain increased after the use of Autopilot compared to the regular class programme.

Success overall can be measured by looking at both classes during the first five weeks of the intervention. By comparing the percentage of Class 1 students with the potential to make positive changes during Autopilot, with the percentage of students from Class 2 with the potential to make positive changes in the regular class programme, an overall assessment of verbal chain increase can be ascertained. Table 19 and Figure 4 show the percentages of students in each class who made positive changes. All elements are listed.

\section{Table 19}

The percentage of students who made positive changes compared across all areas of instruction, for Class 1 with the intervention and Class 2 without the intervention.

\begin{tabular}{lcc}
\hline & $\begin{array}{c}\text { Percentage of students in } \\
\text { Class 1 who made } \\
\text { positive changes with five } \\
\text { weeks of the } \\
\text { Autopilot programme. }\end{array}$ & $\begin{array}{c}\text { Percentage of students in } \\
\text { Class 2 who made positive } \\
\text { changes with five weeks of } \\
\text { the regular class programme }\end{array}$ \\
Verbal Chains & $88 \%$ & $36 \%$ \\
Alphabet Chain & $100 \%$ & $100 \%$ \\
Letter Names & $100 \%$ & $27 \%$ \\
Letter Sounds & No Potential & $50 \%$ \\
Days of the Week & $85 \%$ & $28 \%$ \\
Months of the year & $57 \%$ & $45 \%$ \\
Counting in 1s & $72 \%$ & $71 \%$ \\
Counting in 2s & $81 \%$ & $30 \%$ \\
Counting in $5 \mathrm{~s}$ & $100 \%$ & $20 \%$ \\
Counting in 10s & & $\mathbf{3 9 . 5 \%}$ \\
Average increase for & & \\
all areas of instruction & $\mathbf{8 5 . 5 \%}$ & \\
\end{tabular}

The average percentage of students who positive changes in Class 1 with five weeks of Autopilot instruction was $85.05 \%$. The average percentage of students who made 
positive changes in Class 2 with five weeks of the regular class programme was 39.5\%. From Table 19 and Figure 4, it can be seen that the use of Autopilot increases the positive scores in verbal chains, letter names and sounds compared to the regular class programme.

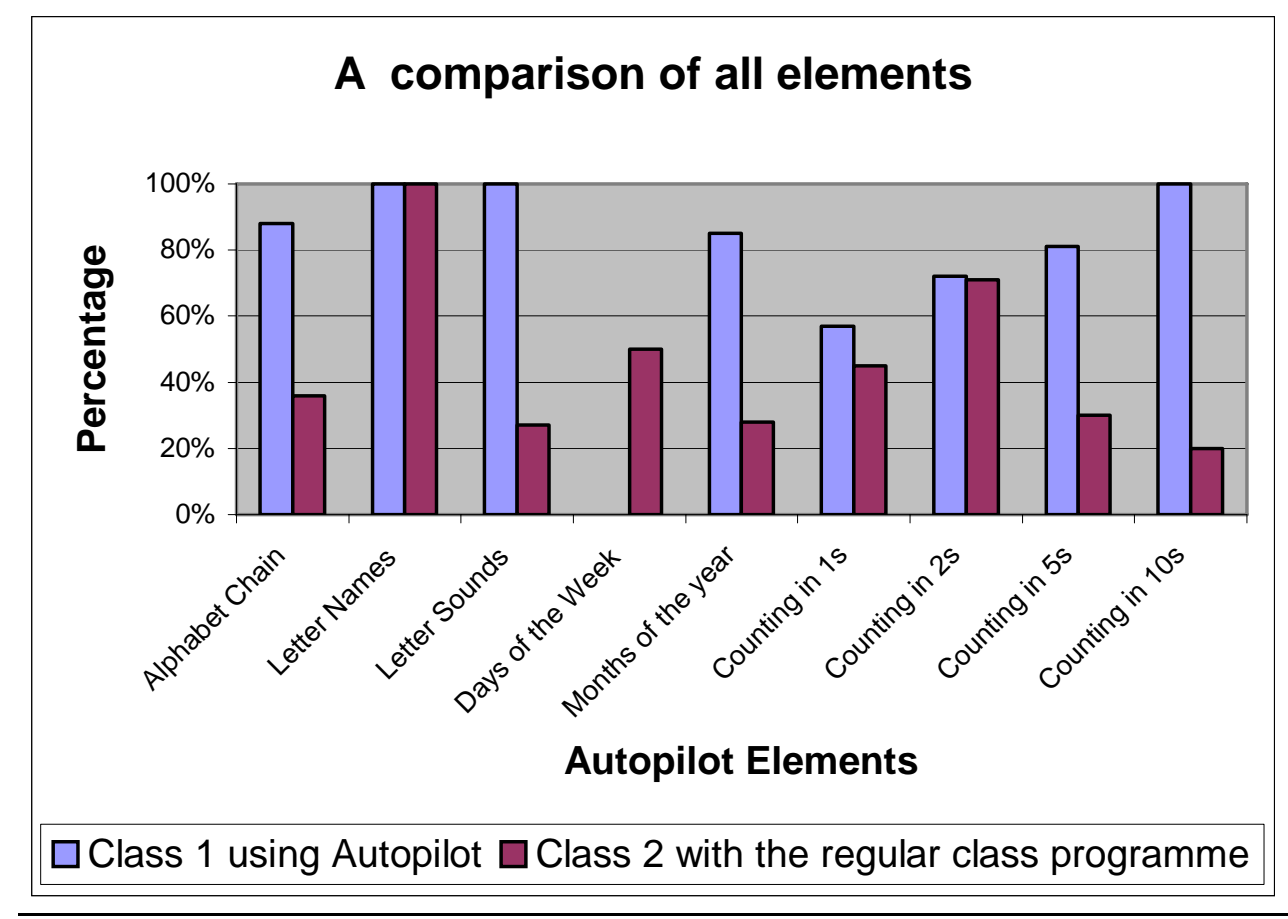

Figure 4

A comparison of the two classes for all the Autopilot elements, showing the percentage of students who made positive changes with the Autopilot programme (Class 1) and with the regular programme (Class 2) at the first assessment (after five weeks of instruction).

\section{Supplementary Question 3}

Does the use of a five week, 15 minutes per day whole class Autopilot programme result in the maintenance of the length of the verbal chain, after 5 weeks of discontinuation? 
Maintenance of the verbal chains and phonetic awareness, could only be measured with Class 1, as they had Autopilot instruction for five weeks and then had the programme removed. Maintenance was measured by two criteria

- Did the length of the chain increase after the programme ceased, meaning the student understood the chain sequence and practised in their own time, without the use of the Autopilot book?

This was possible, as the students often chanted the sequences to themselves during class - free time, with others correcting them and some used classroom equipment as a prompt for the chain, for example an alphabet chart on the wall and a 100s wall chart.

- Did the students maintain the same level after the programme ceased?

\begin{tabular}{|l|c|}
\hline & $\begin{array}{c}\text { Percentage } \\
\text { of students } \\
\text { in Class 1 } \\
\text { who } \\
\text { increased } \\
\text { or } \\
\text { maintained } \\
\text { the chain. }\end{array}$ \\
\hline Chain & $100 \%$ \\
\hline Alphabet & $100 \%$ \\
\hline Days & $91 \%$ \\
\hline Months & $75 \%$ \\
\hline 1s & $91 \%$ \\
\hline 2s & $91 \%$ \\
\hline 5s & $91 \%$ \\
\hline $10 s$ &
\end{tabular}

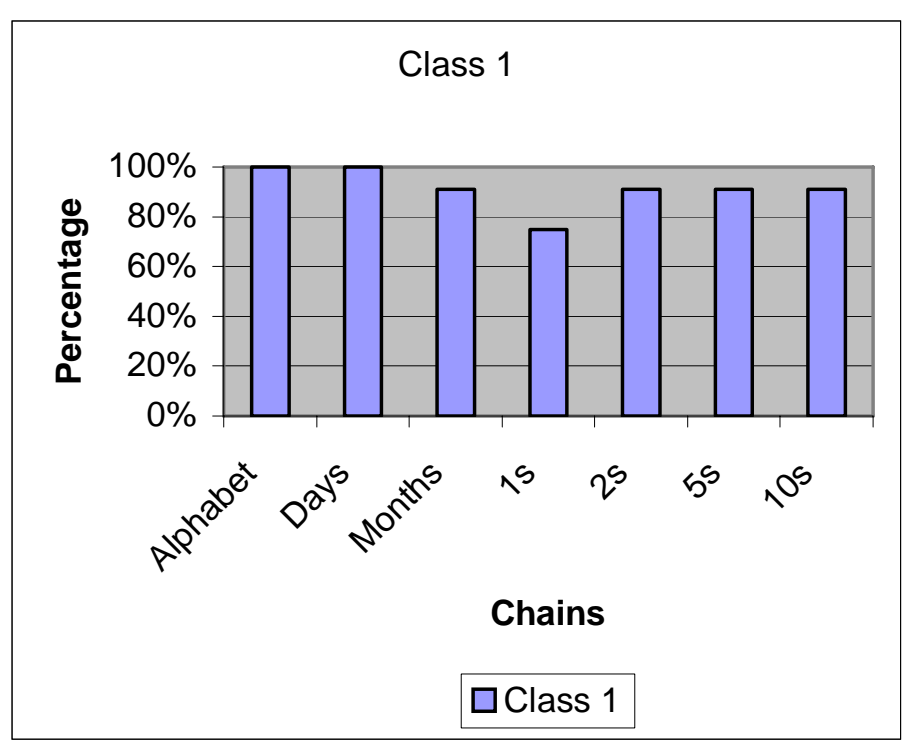

\section{$\underline{\text { Figure } 5}$}

The percentage of students from Class 1 who were able to maintain or increase the length of the verbal chain after ten-weeks. (Five weeks of intervention and five weeks of maintenance).

Figure 5 shows that in Class 1, the percentage of students who maintained or increased the length of the chain varied between 75 and 100\% after the programme had ceased. Of note, the counting in 1s chain scored only $75 \%$. This chain has twice the number of elements compared to any other chain. 


\section{Supplementary Question 4}

Does the use of a five week, 15 minutes per day whole class Autopilot programme increase the students' spontaneous use of the Autopilot charts as a resource during the class programme? For example, do they go to the charts when they need a word, sound etc.?

To address this supplementary question, observations were taken during reading, written expression and maths. There were four observations of 15, 38, 40 and 52 minutes. All instances of spontaneous use of Autopilot were noted.

The first observation was of 52 minutes. There were nine uses of Autopilot, seven by individuals or small groups for free reading and the practising of favourite pages and two instances for reference use - a word and a name.

The second observation was for 38 minutes. There were ten instances of use, nine as free reading of favourite pages and new challenging pages (not yet taught) and one for reference.

The third observation was of 40 minutes. There were eleven uses of Autopilot. Eight by individuals or small groups, for free reading and practising of favourite pages, one by an individual who wanted to try a poem for herself and two instances for reference use - a spelling word and a letter sound (tr. from the blends page).

The fourth observation was of 15 minutes. There were seven uses of Autopilot. One by the teacher guiding "Buzz in 5s," three by individuals or small groups for free reading and practising of favourite pages and three instances for reference use for spelling words.

In the 145 minutes of observation, Autopilot was used for reference on eight occasions at a rate of once every 18 minutes. Although this use seems low, the teachers comments from the post intervention questionnaire / survey are quite telling.

\section{Teacher 1 commented}

"They use it spontaneously during written expression. They use it to find the correct spelling of students' names, days and months. It is used every day as a free reader.” She added, “ They seem to know a lot more and use it for confirming letter sounds”

Teacher 2 commented

"Yes they particularly use it during Maths as a back up activity for counting and counting on. It's used for finding shapes like oval. They use it for 
reciting days and months. It's a great intro to Maori words. They use it everyday as a free reader and quite a few children use it to find how to write words. When they want to find something they seem to know what page it's on.”

Students' comments

Three made reference to it being used for story writing - spelling. They commented that it was a resource for them to look up a spelling word or useful for finding things.

\section{Supplementary Question 5}

Does the use of a five week, 15 minutes per day whole class Autopilot programme have benefits for the students' use of the knowledge in other curriculum areas? For example, do they use the knowledge of counting sequences during the regular Maths programme?

To answer this question, the researcher asked the two teachers this question as part of the teacher survey. Their replies were:

Teacher 1 commented

"Yes it's an extra to the Reading programme and used as a settler after morning tea. It's helped with spelling knowledge and as a resource for Maori. They use it for sounding out words, as a quiet group activity and for private games of "Buzz.” Its also a great resource for poems.”

Teacher 2 commented

"It was a great resource when counting in 2 s and 5 s, finding shapes etc. I wasn't pleased with the original results, so I did a section on Algebra. (NB) It's helped them learn each other's names.

NB This is a significant comment and will be explained during Chapter 5

\section{Supplementary Question 6}

Does the use of a five week, 15 minutes per day whole class Autopilot programme lead to deeper understanding of the concepts used in the verbal-chains? For example, do students who have been exposed to reciting the alphabet have a greater understanding of letter sounds and names? To answer this question the teachers were questioned and the students’ work was sampled. 


\section{Teacher 1 commented}

"Yes. Letter names and sounds are not confused anymore. They have a greater understanding of vowels and vowel sounds. It reinforced the work we did on blends. They are now able to recite months / seasons. They can count on and count in $5 \mathrm{~s} "$

\section{Teacher 2 commented}

"Yes in writing. They use it to go and find a word that they know it is there rather than guess it. Some of them have made their own booklets of Autopilot in their free time. It's helped with counting in $2 \mathrm{~s}, 5 \mathrm{~s}$ and doing "Buzz”." She added “They can find letters and words and sounds in it, like o and oval, when they need to. They are more aware”

Samples of students' work were also examined to determine whether or not any improvement had been made in the students' out of context phonemic awareness. Students' written language exercise books were examined for instances where the most commonly mis-sounded letters may have been used. This was a difficult task, as this class used the Graves (1983) approach to written language, where any attempt at a letter or word was acceptable. It was difficult for the researcher to decipher what the writer had intended to write or sound, unless the class teacher had corrected the work afterwards and provided a script that could be compared.

\section{Data from the students}

\section{Student $1 / 1-$ a prolific writer}

- e sound misused in 6 / 6 samples of an unknown CV(e)C words before the intervention, after the intervention 2 correct uses and 0 incorrect. A 100\% improvement.

- $\mathrm{u}$ sound misused in 2 / 2 samples of an unknown $\mathrm{CV}(\mathrm{u}) \mathrm{C}$ words before the intervention, after the intervention 1 correct uses and 2 incorrect. A 33\% improvement.

- One correct use of $\mathrm{x}$ in a word after the intervention, where no previous samples found. 
- Chronic error with $r$ as last letter in CVCr before the intervention 6 / 6 errors. After the intervention 3 correct uses and 3 incorrect uses, a 50\% improvement

- $\quad$ No uses of Qq

Student $1 / 3$

- e sound misused in 7 / 7 samples of an unknown CV(e)C words before the intervention, after the intervention 2 correct uses and 1 incorrect. A 66\% improvement.

- u sound misused in 3 out of 3 samples of an unknown $\mathrm{CV}(\mathrm{u}) \mathrm{C}$ words before the intervention, after the intervention five correct uses and one incorrect. An 83\% improvement.

- No uses of Qq or Xx,

- One correct spelling of Saturday and one correct spelling of Monday after the intervention, where both were incorrectly spelt previously on all occasions.

Student $1 / 9$

- e sound, u sound, misused in 3 / 3 samples of an unknown CV(e)C and CV(u) words before the intervention, after the intervention 2 correct uses and 1 incorrect. A 66\% improvement.

- $\quad$ No uses of Qq or Xx

Unfortunately, there were too few samples from other students. Most other students did not have more than one example of incorrect use. However, the teachers' comments are relevant as both teachers commented that Autopilot had increased the students' knowledge of discrete elements of the verbal chains: the alphabet, days of the week, months of the year and rote counting.

Teacher 1 commented

"It has definitely helped with rote counting, they can now count in 5s, they have a greater understanding of blends (not part of the assessment) and the idea of letter names and sounds. They are not confused any more. They have a greater understanding of vowels and vowel sounds. They now know their months and like practising on their own.”

Teacher 2 commented

"They can count in 2s and 5s, something they struggled with before, it is especially helpful with Buzz. It helped particularly in Maths, around shape 
knowledge (not part of the assessment). They seem more aware of letter sounds and names as its really good for story writing.”

\section{Supplementary Question 7}

Does the use of a five week, 15 minutes per day whole class Autopilot programme lead to generalisation of the skills to other contexts? To answer this question the teachers were interviewed.

Teacher 1 commented,

"Yes they have a greater understanding of sounds / letters and blends. They have counting sequences sorted out. They know lots more fruit and vegetable names.”

Teacher 2 commented,

"Yes. They have a greater understanding of sounds and letters for story writing. I find it great after play as they are now self-directed and enjoy the rhythm of the pages. They use it as a reader in free time.”

\section{Supplementary Question 8}

Does the use of a five week, 15 minutes per day whole class Autopilot programme help students in their understanding of basic maths / language concepts? To answer this question both the teachers and students were interviewed and surveyed. The students had more specific questions regarding their enjoyment of the programme, being a tutor and what they had learned from the programme.

Teacher 1 commented,

"Yes. Names and letters are not confused the same. They know vowels and vowel sounds. They use the ideas in Maths like “ Buzz” It's great for counting.

They now know $x$ and the $x$ sound.”

Teacher 2 commented,

"Yes. They know that the sounds and the letters are in Autopilot if they need them. I pick someone to lead and then they self-start. I provide it as a resource for reading, it's an extra.” 
The students were also surveyed and their opinion was sought on; what they thought of Autopilot, how had it helped them with their schoolwork, if they enjoyed it what parts did they enjoy, was it fun being a tutor and what had they learned from Autopilot (Appendix G)

All pupils (26) said that they enjoyed the sessions and liked having it in the room. Five students commented that sometimes it was boring - especially counting to 100 . Other comments in this section were:

"It's good, you learn the months."

"Sometimes the pointer goes very fast."

"It helps me find words at story writing time."

“Sometimes its boring when it's a page you know really well and can do it eyes shut.”

How has it helped you with your schoolwork?

Most commented on elements of the programme that helped them, specifically things they knew now, which they did not know before the programme was introduced. The shapes pages and the poems proved the most popular. Some commented (4) on the usefulness of it in the room as a resource. Three made reference to it being used for story writing - spelling. "Something to look up, to help, to find things, to spell." Of the elements being assessed, counting in $5 \mathrm{~s}$ was the most popular. There were negative comments about the length of the counting in 2s sequence.

"Its good for spelling names."

"I learned new shapes.”

"I can do the countdown and count in 5s and 10s."

"I like counting in 5s and learning the new poems."

"I know what a penny farthing is."

"It helps with Buzz."

"It helps me with my reading and stuff."

Did they enjoy it, if so which parts?

All commented that they enjoyed it, $100 \%$ affirmation. There were five who commented on the boring bits. The best parts varied with no firm favourite pages 
although the poems and shapes were the most accepted. The worst pages were the Maori language pages. These were a struggle for most students.

"I like the poems, they're fun.”

Was it fun being a leader? Why?

Those that were trained to be tutors responded favourably to the responsibility and the role, especially having the control of the pointer. There were many comments about using the pointer and its usefulness in helping to focus to the text.

"It's hard being the leader, you have to take lots of breaths around half way through.”

"I like using the wand."

“The pointer helps you slow down.”

“The leader helps by pointing."

"If you are a leader you get to sit in a chair and use a pointer. When kids get stuck you show them how."

"When you're the leader you get to point, its fun choosing the pages."

"It's bestest being the leader."

“Our pointer got changed as it got snapped at reading time, it's a new golden wand, I like it - Zap!”

"You can hear all the voices when you're pointing."

"I never got to be a leader, I wish I was picked."

What have you learned from Autopilot?

These comments also varied considerably. Most made comments about the pages they liked, shapes, transport, counting in fives or the poems.

"It helps me with my reading and stuff"

"I learned parallelogram”

"I learned how to count in fives"

"I learned the months" 
The data shows that Autopilot is a useful resource for the teaching of the verbal chains, especially months of the year, counting in 5s and 10s and for improving individual phonemic awareness. Both teachers and students commented positively on its usefulness, not only as a resource but as a programme of instruction. 


\section{Chapter Five}

\section{Discussion and Conclusions}

This research investigated the tool Autopilot and the way the programme is used in Christchurch classrooms, in an endeavour to find whether its widespread use is justified. This chapter will review the research and present a conclusion based on the research. The chapter will then look at what the research tells us about how the programme operated and will discuss any limitations on the research's success or otherwise.

\section{Aim of the Research:}

Does a five week, 15 minutes per day whole class Autopilot programme, increase the Yr. 2 students' understanding and knowledge of the alphabet, days of the week, months of the year and rote counting, for students who have not reached proficiency and maintain the levels for those students who have reached proficiency?

When all elements of the programme were compared (Table 19 and Figure 4), it is clear that Autopilot can be regarded as a successful strategy for teaching verbal chains. The number positive changes or increases in the length of the verbal chains during the five weeks of Autopilot instruction is twice that of the regular classroom programme over the same five week period.

What makes Autopilot so successful? Observations and interviews have found a number of factors that may explain the success of the programme.

Presentation of the programme.

Autopilot is a bright large print programme. The appeal of the pages and the appeal of the success from completing the pages work together. Operant conditioning occurs (Skinner, 1938). Success breeds success. The children enjoy the programme as they are rewarded verbally and intrinsically. In 1992 Gagné, Briggs and Wager 
identified a set of conditions for learning that included nine instructional events and their corresponding cognitive processes. All nine occur during a regular Autopilot session; gaining attention (reception), informing learners of the objectives (expectancy), stimulating recall of prior learning (retrieval), presenting the stimulus (selective perception), providing learning guidance (semantic encoding), eliciting performance (responding), providing feedback (reinforcement), assessing performance (retrieval) and finally enhancing retention and transfer (generalisation).

The regularity and predictability of the programme.

Moving information from short to long-term memory requires regular rehearsal (Gagné, 1985). By rehearsing the verbal chains every day, verbal associations begin, "chunking” (Nolan, 1973) occurs and the sequences increase in accuracy and in length. The teachers identified that some students are comforted in the familiarity of the programme, particularly as it is used at the same time each day. These points support Gagné, Briggs and Wager (1992) guidelines on the conditions of learning theory, particularly the processes of presenting the stimulus and providing learning guidance.

It is non-threatening.

Students can take risks without the embarrassment of failure in front of their peers. For behaviour to be shaped, there needs to be reinforcement through successive approximations of the desired response, (Cooper et al. 1987; Skinner, 1938). Autopilot is non-threatening and students are reinforced and praised for making “guesses” or successful approximations. There is variable reinforcement (Ferster \& Skinner, 1957) occurring, with praise from both the tutor and the teacher. The instruction uses the Direct Instruction approach (Carnine et al.) in a group situation where students are praised through a hierarchy including praise and rewards (stickers, being allowed to lead). Peer mediated instruction was considered by the students to be a successful strategy. They found it easier to take a chance under the direction of a student tutor than in other class learning situations. Rosenbaum (1973) researched the concept of applying techniques of drill and practice, to language skills learning. The techniques used in Autopilot are successful peer mediated instruction sequences similar to the Rosenbaum model. Some students may have absorbed the sequences by observation of the model over successive sessions (Bandura, 1977). 
Rhythm of the language.

A key component of successful reading practice is being able to identify the rhythm and nuances of the English language (Bradley \& Bryant, 1983). Most pages and sequences of Autopilot are "chant like”, which the students find appealing. This was particularly noticed with the counting in fives and months of the year, where students beat out or kept time with the sequence. Adams (1990) researched phonemic awareness and found that before students can progress they need to be able to hear rhymes and alliteration. Autopilot provides opportunity to practise rhythmic sequences.

\section{Pace of the sessions}

All sessions were over in fifteen minutes. Few pages took more than $1 / 2$ a minute each. The sessions were quick paced with pages constantly turning. The students became familiar with the sequence of pages and looked forward to their favourite pages. All students knew that the weekly poems (a popular activity) concluded the sessions.

\section{Peer mediated instruction.}

The singularly most important impact on the success of the programme was the peer mediated instruction process. Ausubel (1968) identified that all knowledge is social in nature and that learning occurs in the context of social interaction where knowledge is constructed rather than absorbed. All the learning interactions within Autopilot are at the student-to-student level where learners are able to take risks, accept challenges and reconstruct the information so that it makes sense to them. Vygotsky (1978) added that the processes occur within the zone of proximal development, the zone is a measure of what a student already knows and what he has the ability to learn with the help of a peer. Autopilot provides that peer relationship, through the daily use of a peer mediated instruction.

Without doubt, all students enjoyed the opportunity to be a tutor. Students responded very favourably to having other students tutor them. The tutoring approach where 
students support each other's learning is well researched and Autopilot confirms that peer mediated instruction is a successful strategy for Yr. 2 students to use when learning verbal chains.

\section{Modelled instruction.}

Autopilot relied heavily on the teacher modelling to students (future tutors), the correct process, pace and session information needed for each instruction time to move without other students losing interest. The teacher models the correct process to students, who themselves model to other students. This scaffolded instruction supports Wood et al (1976) metaphor of help, provided by an expert (the teacher) to the novice (the trainee tutor). Although the instruction occurs within a class context, it supports the Model - Lead - Test strategies of direct instruction (Kameenui \& Simmons, 1990)

\section{Cuing and signalling techniques}

Students were successfully cued to the tasks, both orally (when the tutor read the name of the page), aurally (when they heard the familiar sequence begin) and when they heard the rhythm of a familiar rhyme. The most important cue was the pointer. All students identified the pointer, as a successful strategy to guide them through the pages. The use of a pointer for early reading is well documented (Becker, 1977, Clay, 1979, Boyes, 2001). The skills of one to one correspondence, line to line sequencing and developing a literacy set all occurred with the use of the pointer.

\section{Autopilot as a resource}

Both students and teachers identified the importance of having the book readily available throughout the day for students to use in a variety of ways, these included:

- Practise sequences

- Use a group strategy

- Private reference

- Spelling resource

- Concept resource (to find a shape etc.)

- Teaching tool 
- Poetry sheet

Students were able to practise at their leisure both familiar and unfamiliar pages in a non-threatening way. The resource was always available.

\section{Teacher acceptance and enthusiasm}

Both teachers were familiar with the resource before the research began. They were enthusiastic in their approach to the programme and believed that it was a successful programme. Their belief and enthusiasm rubbed off on the students. They wanted to improve and succeed. Both teachers praised the students as they undertook the tasks. This occurred even when the teacher had no direct involvement with the session. For example, the teacher may have been marking at her desk with a tutor running the session, but the teacher was still able to make positive comments on the current task, just by listening to the class undertaking the sequences.

\section{Limitations of the research}

The age of the students

The days of the week and recognising letter names pages, were less successful than other pages, as most of the students were near the ceiling level before the programme began. Both classes were Yr. 2, who had been exposed to letter names and days of the week formats in their regular class programme. If the researcher had undertaken the research with a class of Yr. 1 students who may have had little exposure to days of the week or letter names, there may have been a greater number of students that could have benefited from the experience. Some chains may be more suitable for younger students and others for older students. The alphabet chain may be more suited to a Yr 1 class.

The age of the students limited the selection of suitable tutors. Although each class had ten students who could read well, some tasks, particularly counting in twos proved difficult for some tutors. 
The sample size had a significant impact on the research. Although class 1 had 12 students taking part in the research and class 214 students, the sample proved to be too small when the ceiling effect was taken into account. For example, when the researcher examined the data for days of the week, there were too few students with the potential to change in either class for the data to be valid. If more students from both classes had been given permission to take part in the research, there may have been a greater potential for change to take place.

\section{Vested interest in the research}

The researcher works for the Aranui RTLB service. The Aranui RTLB service developed the Autopilot programme into the form used for the research. Both the researcher and the RTLB Service have a vested interest in the success of the programme. This may have impacted on the results as the researcher introduced the programme and trained the teachers. The way in which the teachers responded to the programme may have been affected by their knowledge that the programme was prepared and owned by the Aranui RTLB service and the fact that the RTLB worked on a regular basis in the school.

\section{The Ceiling Effect}

It is difficult to compare the effectiveness of a programme between a control group and a treatment group when the opportunity to progress is limited by the amount of progress that can be made. An example of this is the reciting of the alphabet. A high proportion of one class (five out of fourteen) only made errors on the last element -

z. Therefore their opportunity to improve was limited compared to the other class, where only two students had a last element error.

Exposure to baseline data.

One teacher admitted that she changed her class programme after viewing the initial baseline data. The exposure to the baseline data had an impact on the way she approached her Maths lessons. This may have affected the results for the rote- 
counting sequences counting in $1 \mathrm{~s}$ and $2 \mathrm{~s}$, but results in counting in $5 \mathrm{~s}$ showed that the class made progress during the Autopilot phase at a rate greater that during class instruction by the teacher.

\section{Previous experience with Autopilot}

There were some students from both classes who had been exposed to Autopilot in previous classes. The students who had been exposed to the programme in other classes used Autopilot as part of a remediation programme in their Yr. 1 year. This did not have a direct affect on the data, as these students progressed at the same rate as all other students.

\section{Choice of Research Options}

Autopilot has a variety of pages and tasks, from poems to times tables. It includes concepts as well as verbal chains. Many of the students identified that their favourite pages from Autopilot were not the pages being researched. The researcher felt that of the all the pages in Autopilot, verbal chains would be the easiest to assess, as there are definite start and finish points and some finality to the task. In hindsight it may have been better to assess tasks that were totally unfamiliar to the students, for example the blends or digraph pages, as students had not been exposed to these at all. This area may be researched in the future.

\section{Suggestions for future research}

Although Autopilot has been proved to be a successful strategy with Year 2 classes, its use in other levels of the school has not been investigated. Teachers in other schools have indicated they have had success when using Autopilot for:

- Times tables

- Maori Language

- Spelling rules

This is an area that needs further research. 
It has been suggested that concepts rather than verbal chains should been researched, especially for the learning of shapes, fruit and vegetable names and Maori words for colours etc.

The original intention of Autopilot, when Sue Garden initiated the programme, was to improve the learning levels of Maori students by using a preferred Maori learning style. Recently there has been a move by Maori scholars, for schools to be more aware of preferred Maori learning styles. If a Maori version of Autopilot could be produced and presented to Whanau or Kurakaupapa, then this would provide a new area for research.

\section{Conclusion}

No one approach is the "right approach" to the learning of verbal chains. Teachers need to be able to use different ways to teach different tasks. The approach of using rote learning with it elements of modelling and scaffolding and whole class reciting, seems to suit the task of learning the verbal chains of days, months, counting sequences and the alphabet. Verbal chaining in rote learning sequences is the only way to learn some sequences. The New Zealand curriculum in maths states that students must be able to rote count in $1 \mathrm{~s}, 2 \mathrm{~s}, 5 \mathrm{~s}$ and $10 \mathrm{~s}$. They expect teachers to teach rote learning. Autopilot is a successful tool for this process. 


\section{$\underline{\text { References }}^{\mathbf{i}}$}

Adams, M. J. (1990). Beginning to read: Thinking and learning about print. Cambridge, MA: J Bolt, Beranek and Newman Inc.

Anderson, L., Evertson, C., \& Brophy. J. (1979). An experimental study of effective teaching in first grade reading groups. The Elementary School Journal, 79 (4), $193-222$.

Ausubel, D. P. (1968). Educational psychology: A cognitive view. New York: Holt, Rinehart \& Winston.

Baines, L., \& Stanley, G. (2000). We want to see the teacher: Constructivism and the rage against expertise. Phi Delta Kappa, 82 (4), 327-330.

Ball, E. B., \& Blachman, B. (1988). Phoneme segmentation training: Effect on reading readiness. Annals of Dyslexia, 38, 209-225.

Ball, E. B., \& Blachman, B. (1991). Does phoneme awareness training in kindergarten make a difference in early word recognition and developmental spelling? Reading Research Quarterly, 26 (1), 49- 66.

Bandura, A. (1977). Social learning theory. Englewood Cliffs, N.J: Prentice-Hall.

Baroody, A. J., \& Price, J. (1983). The development of the number word sequence in the counting of three year olds. Journal for Research in Mathematics Education, 14, 361 - 368.

Becker, W. (1977). Teaching reading and language to the disadvantaged- what we have learned from field research. Harvard Educational Review, 47 (4), 518543.

Bliss, J., \& Askew, M. (1996). Effective teaching and learning: Scaffolding revisited. Oxford Review of Education, 22 (1), 37-61.

Boyes, K. (2001). Creating an effective learning environment. Upper Hutt: Spectrum Education.

Bradley, L., \& Bryant, P. (1983). Categorizing sounds and learning to read - a causal connection. Nature 301 (3 February) 419 - 421.

Brown, D., \& Thomson, C. (2000). Cooperative learning in New Zealand schools. Palmerston North: Dunmore Press.

Campbell, D., \& Stanley, J. (1963). Experimental and quasi-experimental designs for research on teaching. In N. L. Gage (Ed.), Handbook of research on teaching. Chicago: Rand McNally.

Carnine, D., Silbert. J., \& Kameenui, E. (1997). Direct instruction reading. Columbus Ohio: Merrill. 
Carpenter, T. P., \& Moser, J.M. (1984). The acquisition of addition and subtraction: Concepts in grades one through three. Journal of Research in Mathematics Education, 15, 179-202.

Clay, M. (1979). The early detection of reading difficulties ( $3^{\text {rd }}$. ed.), Auckland, New Zealand: Heinemann.

Colarusso, R., \& O’Rourke, C. (1999). Special education for all teachers (2nd ed.). Dubuque, Iowa, USA: Kendall / Hunt Publishing Company.

Cook G. (1994). Repetition and learning by heart: an aspect of intimate discourse, and its implication. ELT Journal, 48 (2), 133-141.

Cooper, J., Heron, T., \& Heward, W. (1987). Applied behavior analysis. Columbus, Ohio: Merrill.

Danielson, E. (2000). The importance of nursery rhymes. ERIC Clearing House (ED442117).

Davis, G., Pearn, C., Price, G., \& Smith, K. (1997). Connections between counting and reading. Paper presented at 1997 SEMT 97, International Symposium on Elementary Mathematics Teaching, Prague.

Department of Education (1985). Beginning school mathematics, module 1, Wellington: Schools Publications Branch.

Department of Education (1985). Reading in junior classes, Wellington: Schools Publications Branch, Ministry of Education, Learning Media.

Edwards, F. (2003). Many faces: Factors affecting the achievement of NESB students in mathematics, 21. Wellington: Learning Media.

Fazio, B. (1996). Serial memory in children with specific language impairment: Examining specific content areas for assessment and intervention. Topics in Language Disorders, 17 (1), 58-71.

Ferster, C. B., \& Skinner, B. F. (1957). Schedules of reinforcement. Cambridge, MA: Cambridge Publication.

Flett, A., \& Conderman, G. (2002). Twenty ways to promote phonemic awareness. Intervention in School \& Clinic, 37 (1), 242-245.

Frank, A. (1989). Counting skills - A foundation for early mathematics. Arithmetic Teacher, 37, 14-17.

Fuson, K. C., Richards, J., \& Briars D. J. (1982). The acquisition and elaboration of the number word sequence. In C. Brainerd, (Ed), Progress in logical development: Children's logical and mathematical cognition, New York: Springer, 1 (22), 33-92. 
Fuson, K. (1988). Children's counting and concepts of number. New York: SpringerVerlag.

Fuson, K. C. (1990). Conceptual structures for multiunit numbers: Implications for learning and teaching multi-digit addition, subtraction, and place value. Cognition and Instruction 7 (4), 343-403.

Gagné, R. (1985). The conditions of learning and theory of instruction ( $4^{\text {th }}$ ed.). New York: Holt, Reinhart \& Winston.

Gagné, R., Briggs, L., \& Wager, W. (1992). Principles of instructional design (4 ${ }^{\text {th }}$ ed.). Englewood Cliffs, NJ: Prentice Hall.

Gautrey, F. (1991). Cross age tutoring in Frankley. Reading 24 (1), 21-27.

Gill, R. (1983). Learning by heart. The Use of English, 34 (3), 51-54.

Graves, D. (1983). Writing: teachers and children at work. Exeter, New Hampshire: Heinemann.

Hall, T., \& Stegila, A. (2001). Peer Mediated Instruction and Intervention. Retrieved January 20, 2004 from http://www.cast.org/ncac/index.cfm?i=2953

Higgins, J. (1999). Teachers' pedagogical content knowledge and classroom practice in number concepts in mathematics in the third year of schooling. Paper presented at the NZARE/AARE Annual Conference, Melbourne.

Jensen, A. R. (1974). Interaction of Level I and Level II Abilities with race and socio-economic status. Journal of Educational Psychology, 66 (1), 99-111.

Johnson, D. W., Johnson, R. T., Stanne, M.B. (2000). Cooperative Learning Methods: A Meta-Analysis. Retrieved January 20, 2004, from http://www.co-operation.org/pages/cl-methods.html

Junge, B. (1970). The effect of bilingualism on rote learning. Colorado Journal of Educational Research, 9 (2), 10-13

Kameenui, E., \& Simmons, D. (1990). Designing instructional strategies. Columbus, Ohio: Merrill Publishing Company.

Katz, L. G. (1986). Current perspectives on child development. Music Education Bulletin, 86, 1-9.

Kember, D. (1996). The intention to both memorise and understand: Another approach to learning. Higher Education, 31, 341-354.

Leitch, R. (1996). Every kid can learn. Book A. Christchurch: User Friendly Resource Enterprises.

Limbrick, E., McNaughton, S., \& Glynn T. (1985) Reading gains for underachieving tutors and tutees in a cross-age tutoring programme. Journal of Child Psychology and Psychiatry, (26) 6, 939-953 
Limbrick, L., McNaughton, S., \& Cameron, M. (1985). Peer power: Using peertutoring to help low-progress readers in and secondary schools. SET 2, Wellington: New Zealand Council for Educational Research, 3-26.

MacDonald, T. (1975). Rote drill: A neglected basis for mathematics teaching. The Australian Mathematics Teacher, 31 (3), 118-122.

McConkey, R., \& McEvoy, J. (1986). Games for learning to count. British Journal of Special Education, 13 (2), 59-62.

McNaughton, S., Glynn, T., \& Robinson, V. (1981). Parents as remedial reading tutors: Issues for home and school. Wellington, N.Z.: New Zealand Council for Educational Research.

Metge, J. (1990). Te kohao o te ngira. Culture and learning. Wellington: Learning Media.

Ministry of Education (1992). Mathematics in the New Zealand curriculum. Wellington: Learning Media,

Ministry of Education (1993). The New Zealand curriculum framework. Wellington: Learning Media.

Ministry of Education (1994). English in the New Zealand curriculum. Wellington: Learning Media.

Ministry of Education (1996a). Special education 2000. Wellington: Learning Media.

Ministry of Education (1996b). The learner as a reader. Wellington: Learning Media Limited.

Ministry of Education (1999). Report of the Literacy Taskforce, released by Minister of Education Nick Smith on Tuesday 13 April, 1999

Ministry of Education (2001). Resource teacher: Learning and behaviour (RTLB) clusters. Wellington: Ministry of Education, Special Education Unit.

Mitchell, R., \& Martin, C. (1997). Rote learning, creativity and 'understanding' in classroom foreign language teaching. Language Teaching Research, 1 (1), 127.

Nolan, J. (1973). Conceptual and rote learning in children. Teachers College Record, 75 (2), 251-258.

Pollard, A. (1997) Reflective teaching in primary school: A handbook for the classroom ( $3^{\text {rd }}$ ed.). London: Cassell.

Rosenbaum, P. (1973). Peer-mediated instruction, New York: Teachers College Press. 
Samuels, S. J. (1970). An experimental program for teaching letter names of the alphabet ( 9-F-009). Contract No. OEC-6-9-009009-0062). Minneapolis: University of Minnesota.

Scott, L., \& Goetz, E. (1978). Memorization tasks: Rote learning vs. "fun” learning. Lawrence: Kansas University.

Severson, R. (undated). Training paraprofessionals for intensive skill building in an early detection and intervention program. Clearing House Code - Teacher Education. ERIC code ED045548.

Silbert, J. C. D., \& Stein, M. (1981). Direct instruction mathematics. Columbus, Ohio: Charles E. Merrill Publishing Company.

Simpson, J. (1997). Getting unstuck in maths: Building mathematical memory with rapid reconstruction. Paper presented at the Adults Learning Mathematics Conference $\left(4^{\text {th }}\right)$, Limerick, Ireland, July 4-6, 1997.

Skinner, B. F. (1938). The behavior of organisms. New York: Appleton-CenturyCrofts.

Smilkstein, R. (1993). Acquiring knowledge and using it. Gamut, 16-17, 41-43.

Smith, S. P. (1913). The lore of the whare-wananga. New Plymouth: Thomas Avery.

Snell, M. (1993). Instruction of students with severe disabilities. New York: Macmillan Publishing Company.

Stanovich, K. (1993-94). Romance and reality (Distinguished Educator Series). Reading Teacher 41, (4), 280-29.

Steffe, L., \& Cobb, P., (1988). Construction of arithmetical meanings and strategies. New York: Springer-Verlag.

Stevens, R., \& Rosenshine, R., (1981). Advances in research on teaching. Aspen: Systems Corporation.

Tinkham, T. (1989). Rote learning, attitudes and abilities: A comparison of Japanese and American students. The TESOL Quarterly, 23, 695 - 698.

Topliss, N. (1989,). Rote learning helps pupils grasp maths. Otago Daily Times. 26 April, 1989.

Van Houten, R. (1993). Rote vs. rules: A comparison of two teaching and correction strategies for teaching basic subtraction facts. Education and Treatment of Children, 16 (2), 147-159.

Vygotsky, L. S. (1978). Mind and society: The development of higher mental processes. Cambridge, MA: Harvard University Press. 
Waring, R. (2001). How should class teachers incorporate vocabulary teaching into their classes? Retrieved September 27, 2002 from http://www1.harenet.ne.jp/ waring/papers/eltnews.html.

Watkins, D. (2000). Learning and teaching: a cross-cultural perspective. School Leadership and Management: 20 (2), 161-173.

Wertsch, J. (1985). Culture, communication and cognition. Vygotskian perspectives. Cambridge, England: Cambridge University Press.

Wood, D., Bruner, J., \& Ross, G. (1976). The role of tutoring in problem solving. Journal of Child Psychology \& Psychiatry \& Allied Disciplines, 17 (2), 89100. 
${ }^{\mathrm{i}}$ Autopilot remains the property of the Aranui Resource Teacher of Learning and Behaviour Service (Aranui RTLB)

Permission should be sought from this service, if Autopilot programmes are to be used in schools.

A copy of the Autopilot programme (in the form of a CD disk) is available from the Aranui RTLB Service PO Box 15019 Christchurch. The cost for each disk is $\$ 10$.

The researcher (Mr Kevin White) has permission from the Aranui RTLB service to promote the programme in NZ schools. 


\section{APPENDIX}
A Days of the week
B Concepts on the disk
C Board Approval
D Teacher Approval
E Parent Approval
F Recording Sheet
G The effectiveness of Autopilot (pupils)
$\mathrm{H}$ The effectiveness of Autopilot (teachers) 
Appendix A

Monday

Tuesday

Wednesday

Thursday

Friday

Saturday

Sunday

Saturday and Sunday together are also called "The Weekend" 



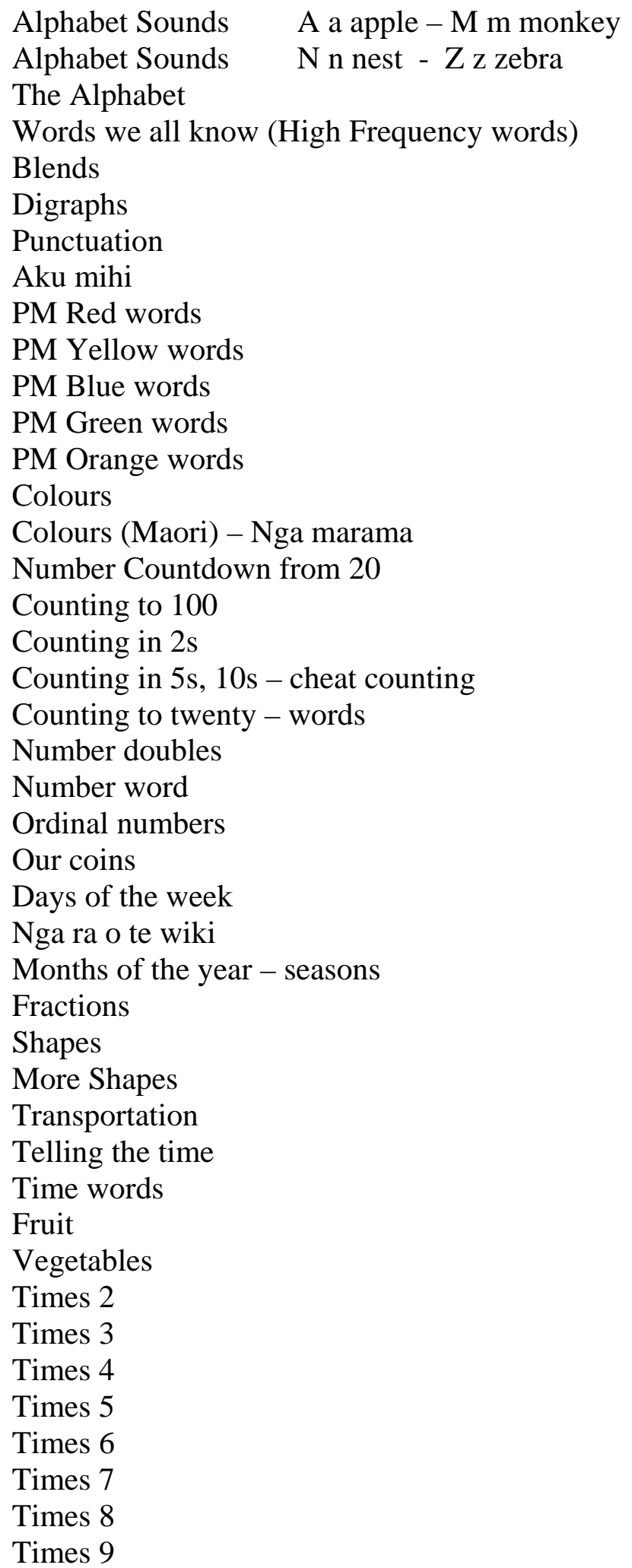


\begin{tabular}{|l|l}
\hline Appendix C & $\begin{array}{c}\text { VICTORIA UNIVERSITY OF WELLINGTON } \\
\text { Te Whare Wananga o te Upoko o te Ika a Maui }\end{array}$
\end{tabular}

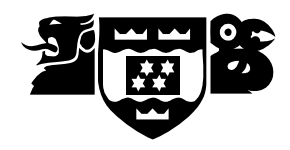

\section{CONSENT TO PARTICIPATION IN RESEARCH}

\section{Chairperson's name:}

The Board of Trustees has had the opportunity to read about the research that Kevin White wishes to undertake with pupils and staff at South New Brighton School. We have had the opportunity to ask any questions.

Pleas tick each box to indicate agreement.

$\square$ We understand that if we agree to the research, Kevin White will be:

- assessing ten pupils from two classes on a number of maths / language concepts that form part of the Autopilot class programme.

- observing two classes as they participate in the programme

- interviewing the pupils and the two teachers using a brief seven minute interview on the use of the Autopilot programme

$\square$ We understand that the information from the interviews, observations and assessments will be included in a thesis for submission to Victoria University of Wellington and may be used in an article or a conference presentation.

$\square$ We understand that the interviews, observations and assessments will be confidential and all information will be securely stored and destroyed one year after the study is finished.

We understand that the school, teachers and pupils will not identified in any part of the report.

$\square$ We understand that the Board of Trustees may withdraw permission for this project at any time before data collection and analysis is complete without having to give reasons of any sort.

We agree that this research may be undertaken at South New Brighton School.

Signed

Date 
VICTORIA UNIVERSITY OF WELLINGTON

Te Whare Wananga o te Upoko o te Ika a Maui

Appendix D

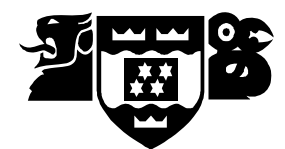

\section{CONSENT TO PARTICIPATION IN RESEARCH}

\section{Teacher Name:}

I have been given the opportunity to read about and discuss the proposed research on the Autopilot programme.

Please tick each box below to indicate agreement.

I understand that Kevin White will:

- collect data from an interview with me at the end of the programme (approximately 10 minutes);

- collect data from students through individual assessment at the beginning and end of the programme and a brief interview at the end of the programme;

- undertake observations of my class programme.

$\square$ I understand that the information from this research will be included in a thesis for submission to Victoria University of Wellington. It may also be used for an article in an academic journal and for a conference presentation.

$\square$ I understand that the information will be confidential and that no information will be shared, except with Liz Jones, Kevin White’s university supervisor. All data will be kept securely and destroyed one year after the completion of the study.

$\square$ I understand that neither my name and any other identifiable characteristics nor those of the students in my class will be included in any report.

$\square$ I agree to participate in the project and will take responsibility for ensuring that Autopilot is included on a daily basis as part of the class programme for the five weeks of the research. I agree to take responsibility for the running of the programme in my class.

$\square$ I understand that I may withdraw my permission to take part in this project, (before data collection and analysis is complete), without having to give reasons of any sort.

I agree to take part in this research.

Signed

Date 
VICTORIA UNIVERSITY OF WELLINGTON

Te Whare Wananga o te Upoko o te Ika a Maui

Appendix E

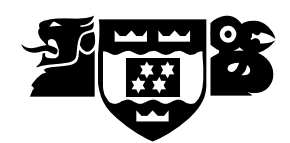

\section{CONSENT TO PARTICIPATION IN RESEARCH}

\section{Parent Name:}

I have had this research explained to me and have had the opportunity to ask any questions. I understand that the information from the interview and assessments will be included in a thesis for submission to Victoria University of Wellington and may be used in an article or a conference presentation.

Please tick each box below to indicate agreement.

$\square$ I understand that Kevin White will:

- assess my child on a number of maths / language concepts that form part of the Autopilot class programme at the beginning and end of the programme (about 5-10 minutes)

- observe the class when participating in the programme

- undertake in a brief, five question, seven minute interview with my child on the use of the Autopilot programme

I understand that the interview and assessments will be confidential and all information will be securely stored and destroyed one year after the study is finished.

$\square$ I understand that my name, my child's name and any other identifiable characteristics, will not be included in any report.

I understand that my child may withdraw from this project without giving any reasons and without penalty. I may withdraw my permission for my child to take part in this project, (before data collection and analysis is complete), without having to give reasons of any sort.

I agree to discuss the research with my child and ask his/her agreement to participate in assessments and interview.

My child has agreed to participate in the research. I also agree for my child to take part in this research.

Signed

Date 
Appendix F

This sheet was used to record the individual responses to the pre / mid / post assessments of the verbal chains.

\section{Data Collection Sheet}

\section{Pre / Post Autopilot Assessment}

$\begin{array}{llll}\text { Datel } & 2 & 3 & \text { Name }\end{array}$

1. Alphabet and Phoneme Knowledge

a. Rote alphabet knowledge - to highest letter in order without error Eg. ABCDEGH scores 5 NB. ( $\underline{G}$ shows first error) Score - Comment

b. Letter names - from a sample list of 10 upper and lower case letters $\mathrm{K}$

$H$

k

B

h

M

b

Q

m

R

$q$

$r$

$T$

$\dagger$

0

0

P

$\mathrm{F}$

$p$

$f$

c. Letter sounds - from sample list of ten upper and lower case letters

VZMTREOUXQ - the latter five being amongst the most to sound (Reading Recovery data). Reading Recovery data also shows that $y$ is one of the most difficult sounds for students to recall, but three vowels are a sufficient in the sample).

v

z

V

m

Z

$\dagger$

M

$r$

$T$

e

R

0

E

u

O

U 
2. Rote Counting in $1 s, 2 s, 5 s$ and $10 s$, to the highest without error

Eg. $123456 \underline{8} 910$ scores 6

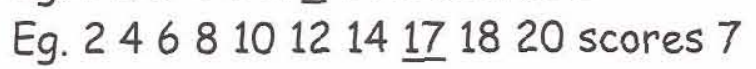

l's

2's

5 's

$10^{\prime} \mathrm{s}$

3. Reciting the days of the week in sequence.

This will need to be modelled first.

"Listen carefully. I am going to tell you the days of the week.

Monday, Tuesday, Wednesday, Thursday, Friday, Saturday, Sunday

Now, I would like you to tell me the days of the week."

Last

Score

4. Reciting the months of the year in sequence.

This will need to be modelled first.

"Listen carefully. I am going to tell you the months of the year.

January, February, March, April, May, June, July, August, September,

October, November, December. Now, I would like you to tell me the Months of the year."

Last Score

\section{General Comments}




\section{Victoria \\ UNIVERSITY OE WELLINGTON \\ Te Whare Wänanga \\ o te Upoko o te Ika a Mäui

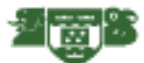

Appendix G
(Reduced format -
the original was two
pages of A4)

The Effectiveness of "Autopilot"

Student identification

Date of interview

Q

Tell me what you thought of Autopilot?

$\ldots$

.

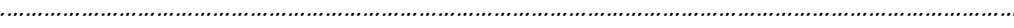

Q2

Has it helped you with you school work? If so, how?

.

(1)

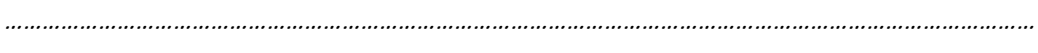

Q3

Did you enjoy doing it? If yes, what parts did you like best?
Q4

Was it fun being a tutor / leader? If yes, why?

....

Q5

What have you learned from Autopilot?

.

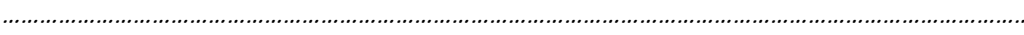

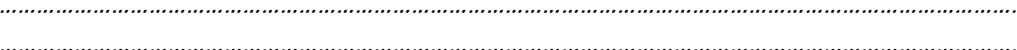

(1) 
Victoria

UNIVERSITY OF WELLINGTON

Te Whare Wānanga

o te Upoko o te lka a Mäui

The Effectiveness of "Autopilot"

Questions for a structured teacher interview.

Teacher identification

Date of Interview

Appendix $\mathrm{H}$
(Reduced format -
the original was two
pages of A4)

Q1

Has the daily use of Autopilot, aided phoneme understanding during written expression? Yes or No

If Yes, please give examples from your observations.

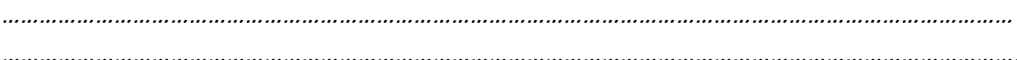

(1)

(1)

Q2

Do students who have been exposed to Autopilot, spontaneously use it as a

resource during the class programme? If yes, how?

(n)

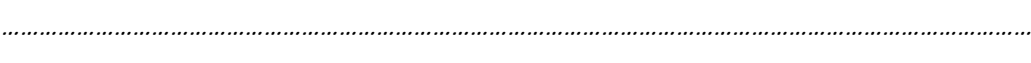

Q3

Has Autopilot affected the class programme? If yes, how?
Q4

Do students who have had daily use of Autopilot, use the knowledge gained in the appropriate curriculum areas? If yes, give examples.

Q

Q5

What types of learning occurs as a result of the introduction of Autopilot?

-

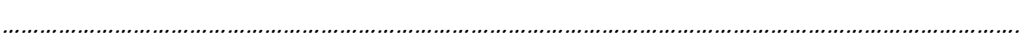

Q6

Does the use of Autopilot lead to deeper understanding of the concepts in the verbal-chains? If yes, give examples.

(n)

(1) .

Q7

Are the concepts used in Autopilot generalised to other contexts? If yes, how? Give examples.

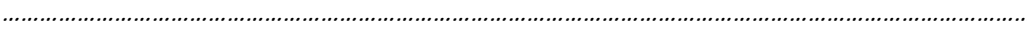

(n) 